\title{
ApoE4: an emerging therapeutic target for Alzheimer's disease
}

\author{
Mirna Safieh", Amos D. Korczyn² and Daniel M. Michaelson ${ }^{1 *}$
}

\begin{abstract}
Background: The growing body of evidence indicating the heterogeneity of Alzheimer's disease (AD), coupled with disappointing clinical studies directed at a fit-for-all therapy, suggest that the development of a single magic cure suitable for all cases may not be possible. This calls for a shift in paradigm where targeted treatment is developed for specific AD subpopulations that share distinct genetic or pathological properties. Apolipoprotein E4 (apoE4), the most prevalent genetic risk factor of $A D$, is expressed in more than half of $A D$ patients and is thus an important possible AD therapeutic target.

Review: This review focuses initially on the pathological effects of apoE4 in AD, as well as on the corresponding cellular and animal models and the suggested cellular and molecular mechanisms which mediate them. The second part of the review focuses on recent apoE4-targeted (from the APOE gene to the apoE protein and its interactors) therapeutic approaches that have been developed in animal models and are ready to be translated to human. Further, the issue of whether the pathological effects of apoE4 are due to loss of protective function or due to gain of toxic function is discussed herein. It is possible that both mechanisms coexist, with certain constituents of the apoE4 molecule and/or its downstream signaling mediating a toxic effect, while others are associated with a loss of protective function.
\end{abstract}

Conclusion: ApoE4 is a promising AD therapeutic target that remains understudied. Recent studies are now paving the way for effective apoE4-directed AD treatment approaches.

Keywords: Alzheimer's disease, Apolipoprotein E4, apoE4 therapeutics, apoE4 lipidation, Anti-apoE4 antibodies, Human apoE-targeted replacement mice

\section{Background}

Senile dementia is one of the greatest medical threats of the twenty-first century. Thus, unsurprisingly, considerable intellectual and financial resources have been invested to forestall this emerging disaster. Unfortunately, to date, these efforts are yet to succeed in identifying a viable solution.

Many disorders of brain function lead to cognitive decline, among which Alzheimer's disease (AD) is considered the most prevalent. The definition of AD itself is not simple. Unique among human diseases, the accepted definition requires a combination of clinical manifestations (i.e., dementia) and structural changes, namely

\footnotetext{
* Correspondence: dmichael@post.tau.ac.il

${ }^{1}$ Department of Neurobiology, Sagol School of Neurosciences, The George S.

Wise Faculty of Life Sciences, Tel Aviv University, Ramat Aviv, 6997801 Tel

Aviv, Israel

Full list of author information is available at the end of the article
}

deposition of amyloid $\beta(A \beta)$ and hyperphosphorylated tau tangles (neurofibrillary tangles) in the brain. Since various other brain disorders can lead to cognitive deterioration comparable to that observed in $\mathrm{AD}$ and, similarly, identical pathological changes can occur in people who do not manifest cognitive decline, diagnoses of $\mathrm{AD}$ require both specific cognitive deterioration and neuropathological changes. It is therefore unsurprising that attempts to focus treatment on deposits have so far resulted in disappointment $[1,2]$.

The term $\mathrm{AD}$ has itself undergone changes in definition. For approximately 50 years, since its first description, $\mathrm{AD}$ was specifically used to describe the development of dementia in younger people who had $\mathrm{A} \beta$ plaques and neurofibrillary tangle deposits; presently, this is termed early-onset AD (EOAD). However, as has been discovered over the years, EOAD results primarily from genetic mutations in certain genes. Nevertheless, 
current demographics being diagnosed with $\mathrm{AD}$ are older people without any of these mutations.

Identification of the specific EOAD mutations enabled the creation of animal models of the disease, with transgenic mouse models revolutionizing $\mathrm{AD}$ research and the development of experimental therapies. Nevertheless, it must be stressed that these models are specific for EOAD [3] and not for the much more common, late-onset form of the disease (LOAD), despite them having been employed for this. Therefore, given the different factors that play a role in both forms of the disease, these approaches have important limitations in their application to LOAD. In addition, the behavior phenotype of mouse models differs substantially from that of human disease. The cognitive deficits of AD mice are rather mild when compared with those of dementia - whereas humans with $\mathrm{AD}$ eventually become helpless and require constant care, the mice remain independent until their death; further, comorbidities, inflammation, and neural loss are less pronounced.

Epidemiologic studies exploring the risk factors for LOAD elucidated a large number of associated factors, including important vascular processes $[4,5]$. Additionally, a number of genetic associations have been revealed by genome-wide association studies [6], the most important of which is the apolipoprotein $\mathrm{E}$ gene on chromosome 17 (APOE gene, apoE protein) [7]. Other polymorphisms are associated with genes related to inflammation and immune responses, lipid metabolism, and endocytosis/intracellular trafficking [8], but none of them are as common nor do they have an effect as strong as that of apoE. To date, attempts to modify the molecular processes involved in $A D$ have mainly targeted $A \beta$ and, more recently, tau [1, 9]; nevertheless, these attempts have been mostly unsuccessful. Herein, we discuss another possible, albeit less popular target - apoE.

\section{Role of apoE}

Several studies have demonstrated the important involvement of apoE in $\mathrm{AD}$. This was first suggested by Strittmatter and Roses [10], who showed that, of the three polymorphic forms of $A P O E$, namely $A P O E 2$, $A P O E 3$, and $A P O E 4$, carriers of $A P O E 4$ are more likely to develop $\mathrm{AD}$. Further, the cognitive changes in the $A P O E 4$ carriers were shown to occur several years earlier, with a dose-dependent effect. Conversely, APOE2 carriers have a 'protective' effect relative to $A P O E 3$ and $A P O E 4$ carriers, and therefore the apoE4 protein appears to be 'toxic', whereas apoE2 is 'protective' against $\mathrm{AD}$. This assumption will be discussed critically herein since, theoretically, all isoforms could be 'protective', with apoE2 having the strongest and apoE4 the mildest effect or, vice versa, all isoforms may have 'toxic' features of varying degrees. It is therefore likely that apoE has several effects, some of which are protective whereas others are toxic, and that apoE4 has the least beneficial expression of these features. This may have important implications, since knowing the dominant effect of apoE4, and whether it is toxic or protective, would affect the therapeutic strategy used to treat apoE-related disease. Importantly, apoE4 has been implicated in numerous processes, including crosstalk with $A \beta$, and shown to have an effect on lipid metabolism and inflammation [11-13]; however, the relative importance of these processes in mediating the effect of apoE4 in $\mathrm{AD}$ remains to be determined.

Another issue of concern is that the serum, cerebrospinal fluid (CSF), and presumably tissue concentrations of the different haplotypes are not equal; carriers of APOE4 have lower serum and brain apoE concentrations than do carriers of the other isoforms [14], and it is possible that some of the apoE effects depend on the apoE concentration rather than its quality. Considering the simplest assumption first, namely that apoE4 is toxic to the brain, may suggest that blocking its action may delay or stop the development of AD. Blocking the apoE4 effect specifically can be achieved by genetic, biochemical, and immunological methods. Such an approach would help the $40-60 \%$ of $\mathrm{AD}$ patients who carry apoE4, whereas, if all apoE forms are in fact toxic (albeit to a different degree), a better approach would be to block all apoE action, at least in the adult brain, if this can be done with impunity.

Additionally, it is important to consider that, although the apoE protein is synthesized primary in the liver, it is also produced in the brain and functions there in many in many capacities, some of which may be relevant to $\mathrm{AD}$. One of the major roles of apoE in the brain, similar to the rest of the body, is related to lipid transport and cholesterol homeostasis [15-17]. ApoE4 was shown to be hypolipidated and less effective than apoE3 in inducing cholesterol efflux, suggesting that the pathological effects of apoE4 are related to lipid metabolism. This assertion and other mechanistic studies, such as the role of interaction of apoE4 with $A \beta$, phosphorylation of tau protein, disruption of metachondrial function, and others discussed in this review, have been studied extensively experimentally, both in whole animals and in isolated tissues in vitro. However, thus far, these studies have not identified one function that can be regarded as the single most likely and important pathway. Nevertheless, the limitations of these experimental methods need to be examined critically. In particular, it should be stressed that none of the available models can be fully considered to be representative models of $\mathrm{AD}$ as a complex disease. Furthermore, the levels of expression of $A \beta$ and tau in AD models are often non-physiological, rendering it difficult to assess the significance of 
downstream signaling effects. In addition, endogenous rodent molecules may react differently with human $\mathrm{AD}$ molecules than do their human counterparts [18]. It is important to also note that not all the genes that have been linked to apoE4 and AD (e.g., TOMM40, which is situated very close to the $A P O E$ gene on chromosome 19 and whose different isoforms are closely linked to $A P O E$ alleles [19]) have been studied at the animal model level.

\section{Impact of the APOE genotype on other diseases}

Numerous studies, backed by meta-analyses, have revealed that $A P O E 4$ is also a risk factor for other diseases [20], including cerebral amyloid angiopathy (CAA) [21], dementia with Lewy bodies (DLB) [22], tauopathy [23], cerebrovascular disease [24], multiple sclerosis [25, 26], and vascular dementia [24, 27], as well as being related to poor outcome following head injury [28, 29]. However, the involvement of $A P O E 2$ in these diseases is less clear, presumably in part due to the low abundance of $A P O E 2$ carriers in the population. The $A P O E$ genotype also plays a role in age-related macular degeneration (AMD), where paradoxically APOE4 is protective [30]. Pathologically, AMD is associated with excessive angiogenesis and is being treated by anti-vascular endothelial growth factor (VEGF) antibodies that reduce excessive pathological angiogenesis [31]. In contrast, $\mathrm{AD}$ and other diseases for which apoE4 is a risk factor are characterized by enhanced degeneration and impaired plastic repair [32, 33]. Animal and cellular model studies revealed that APOE4 is associated with impaired cellular plasticity [32, 34, 35]. It is thus likely that the negative effects of APOE4 in AD are due to this impaired neuronal synaptic plasticity, whereas in AMD, in which the key pathology is increased angiogenesis and vascular plasticity, the effects of apoE4 could be protective due to the reduction in retinal pathological neovascularization [36].

Regarding the association of APOE4 with DLB risk, it has been shown that $A P O E 4$ is a strong risk factor across the DLB spectrum, being associated with an increased likelihood of presenting with dementia in the cortex of a pure synucleinopathy [22]. Accumulating data suggest that this effect of APOE4 on the pathology of DLB is through a non-amyloid-related mechanism, which merits further investigation [22]. Further, it has been recently shown that APOE4 markedly exacerbates tau-mediated neurodegeneration in a mouse model of tauopathy [23]; this finding, and the observation that tauopathy associated with frontotemporal dementia is associated with increased apoE4 allele frequency, suggest that the involvement of apoE4 in tauopathy may be independent of $A \beta[37,38]$.

Epidemiological studies have consistently shown that $\mathrm{AD}$ patients have an increased load of cerebrovascular diseases [39]. Since apoE is a carrier of plasma cholesterol, it is of interest to determine the contribution of cardiovascular disease pathology to dementia in carriers of different $A P O E$ isoforms. Apparently, APOE4 carriers are more likely to develop ischemic cardiovascular diseases (OR 1.68, 95\% CI 1.36-2.09) [40, 41]. Moreover, an autopsy-based study established that APOE4 is a significant risk factor for cerebral ischemia, with a three-fold increase over APOE3 [42]; yet the effect is relatively small and has not been confirmed in other studies [43, 44]. Additionally, accumulating data have confirmed an association between APOE4 and cerebral microbleeds, which may be due to the effect of apoE4 on amyloid deposition around leptomeningeal vessels [45]. Nevertheless, most of these results were based on clinical observations, which are subject to referral bias and diagnostic inaccuracies.

Since APOE4 is the most prevalent genetic risk factor for $\mathrm{AD}$, it is not surprising that the $A P O E$ genotype has been reported to affect the outcome of clinical trials directed at different therapeutic targets [46]. These findings are likely due to indirect effects where the target of the therapeutic treatment interacts with apoE4. In this review, we address the therapeutic potential of treatments by focusing on the APOE4 gene and apoE4 protein as well as on key downstream targets of apoE4.

\section{Review of suggested apoE-driven mechanisms}

The presentation of AD as well as animal and cellular studies led to the generation of several, not mutually exclusive, hypotheses regarding the cellular and molecular mechanisms that may mediate the pathological effects of apoE4. The following section summarizes the main mechanisms by which apoE may be involved in AD.

\section{$A \beta$ metabolism}

$\mathrm{A} \beta$ deposition in $\mathrm{AD}$ patients is more abundant in apoE4 carriers in comparison with non-carriers [47]. Moreover, similar results were observed even in cognitively normal elderly subjects (although this association was weaker than seen in demented individuals) [48-50]. As mentioned above, lower CSF and plasma concentrations of apoE are found in $A P O E 4$ carriers, suggesting that lower levels of apoE might facilitate the accumulation of $A \beta$ in the brain; this was supported by the finding that apoE levels are negatively correlated with $A \beta$ levels in multiple brain regions when analyzed in non-demented individuals [51]. In addition, animal model studies utilizing targeted replacement mice that express human apoE4 or apoE3 and corresponding in vitro studies revealed that apoE4 affects several key steps in the amyloid cascade, including the aggregation and deposition of $A \beta$, which, like in humans, has the isoform dependency of apoE4 > apoE3 > apoE2, and $\mathrm{A} \beta$ clearance from the brain, which 
follows the opposite trend [52, 53]. It has been shown that apoE binds to $A \beta$ and that blocking this binding with a 12-28 fragment of $A \beta$ counteracts key in vivo and in vitro pathological effects of $A \beta$ [54]. All together, these observations suggest that apoE4 may have specific brain area effects in regulating $A \beta$ accumulation and may therefore play a key role in $\mathrm{AD}$ pathogenesis.

Accordingly, apoE4 enhances $A \beta$ production by affecting the activity of gama-secretase [55]. With regards to clearance, apoE4 impairs the lysosomal degradation of $A \beta$, and it is less effective than apoE3 in transporting $A \beta$ across the blood-brain barrier (BBB). Additionally, apoE4 has an impaired ability to facilitate the proteolytic degradation of $A \beta$ by neprilysin and the insulin-degrading enzyme [56-59]. Finally, it has been shown that apoE4 likely promotes $A \beta$ aggregation and stabilizes the $A \beta$ oligomers to a greater degree than apoE3, and that it inhibits the conversion of oligomers into $A \beta$ fibrils through the formation of apoE/A $\beta$ complexes $[48,60]$.

For more detailed information regarding the interaction of $A \beta$ and apoE, see previous reviews $[12,48,59,61-65]$.

\section{Tau phosphorylation}

Hyperphosphorylated tau is a major constituent of neurofibrillary tangles. Analysis of CSF samples from $\mathrm{AD}$ patients and healthy controls revealed that the ratio between phosphorylated and total tau might serve as a biomarker of $\mathrm{AD}[32,66-68]$. Complementary animal models suggest that tau hyperphosphorylation alone can cause neurodegeneration, leading researchers to conclude that hyperphosphorylated tau is toxic to neurons, and suggesting that hyperphosphorylated tau plays a major role in AD neuropathology [66]. This has been observed in several mouse models, including in apoE4-targeted replacement mice in which most of the apoE is synthesized by astrocytes $[69,70]$ as well as in transgenic mice in which over-expression of apoE4 is under the neuronal promoter [71, 72]. Furthermore, tau hyperphosphorylation is enhanced following exposure to stress or injury [73]. Corresponding results have been demonstrated in cell cultures [74].

Two complementary mechanisms have been proposed to explain the effects of apoE4 on tau hyperphosphorylation. Firstly, a direct mechanism based on the fact that apoE3 is more effective in binding to non-phosphorylated tau than apoE4, thereby preventing tau accumulation. Secondly, it has been proposed that apoE4 in neurons can escape the secretory pathway [75] due to its unique structure and that it interacts directly with tau in the cytoplasm to induce its hyperphosphorylation [76]; this proposed indirect mechanism may be mediated by apoE receptor-driven signaling cascades specific to apoE4, which in turn modify the function of tau kinases and phosphatases [77]. In addition, the enhanced ability of
apoE4 to escape the secretory pathway enables it to intracellularly interact with zinc to phosphorylate tau protein through erk activation [78].

\section{Transactive response DNA-binding protein 43 (TDP-43)}

TDP-43, an RNA-binding protein that functions in axon skipping, has recently been shown to be deposited in AD brain. TDP- 43 is present in the brain of $65-80 \%$ of $\mathrm{AD}$ patients and was shown to be associated with progressive hippocampal atrophy. Research investigating the cross-sectional association between apoE4 and TDP-43 by mapping the potential associations between apoE4 and tau, $\mathrm{A} \beta$, and TDP-43, indicates that the deposits of this protein are also increased in APOE4 carriers in comparison to APOE3 and APOE2 carriers [79-81].

\section{Lipid metabolism}

ApoE, which is the brain's most prevalent lipoprotein, is associated with cholesterol and phospholipids as high-density lipoprotein-like particles that play a key role in the distribution and recycling of lipids in the brain [17]. This led to extensive investigations of the possibility that lipids play an important role in mediating the pathological effects of apoE4. Measurement of the brain and CSF levels of docosahexaenoic acid (DHA), an essential $\omega-3$ fatty acid critical for neuronal and brain function [82], revealed that DHA levels are reduced in $\mathrm{AD}$ patients [83] and in apoE4 carriers [84], and that apoE4 increases the uptake and incorporation of DHA into distinct brain areas [85]. Similar results were observed in apoE4-expressing mice [86], wherein the brain's pathological effects of apoE4 were counteracted by feeding mice with a fish-oil high-DHA diet [84, 87]. Further studies revealed that apoE4 is associated with disruption of the BBB [88] and with phospholipid and cholesterol dysregulation [63, 89, 90].

The important role of cholesterol in a variety of cellular mechanisms and its pronounced effects on $A \beta$ levels [91] and related mechanisms suggest that cholesterol is an important player in the pathogenesis of $\mathrm{AD}[92,93]$. It was reported that subjects with both an apoE4 genotype and high cholesterol levels have more pronounced cognitive decline than subjects expressing only one of these risk factors [94]; however, such effects were not seen in other human studies [95]. Mouse model studies revealed that a high cholesterol diet accentuates the pathological effects of apoE4 in targeted replacement mice that express human apoE isoforms and no mouse apoE [87]. It is important to note that, although these studies suggest a link between apoE4 and lipids, they do not provide a clear mechanism nor a therapeutic target.

Analysis of the degree of lipidation of the different apoE isoforms in human CSF and in the brains of apoE-targeted replacement mice revealed that, in both 
human and mice, apoE4 is hypolipidated relative to apoE3, and that brain apoE2 is the most lipidated isoform [96, 97]. The CSF apoE4 high-density lipoprotein-like particles [17] are smaller and less lipidated in apoE4 than in apoE3 carriers $[98,99]$. The lipidation of apoE in the brain is driven by the ATP binding cassette proteins $\mathrm{ABCA} 1$ and $\mathrm{ABCG} 1$, wherein the former drives the initial lipidation of apoE, which is then further lipidated by ABCG1 [100]. Downregulation and deletion of $\mathrm{ABCA} 1$ reduce the levels of plasma and brain apoE and are associated with the formation of smaller apoE-containing lipoprotein particles $[17,101]$ and with the accentuation of the apoE4 phenotype [102]. This led to assessing the possibility that the pathological effects of apoE4 may be related to its hypolipidation and that the lipidating protein ABCA1 may be a promising therapeutic target [103, 104]. Evidence supporting this assertion is presented below (see Approaches directed at the apoE4 protein).

\section{Mitochondrial function}

Extensive research has provided evidence that metabolic alterations resulting from mitochondrial dysfunction occur in $\mathrm{AD}$ [105] and are accentuated in APOE4 carriers. Accordingly, gene expression studies revealed that apoE4 expression in $\mathrm{AD}$, when compared to apoE3, is associated with downregulation of gene transcripts of mitochondrial respiratory complexes I, IV, and V [106, 107], in addition to an isoform-specific effect on the expression of oxidative stress and mitochondrial-related transport proteins [108]. These findings are in agreement with the fact that APOE4 carriers develop AD-like cerebral glucose hypo-metabolism decades before the onset of the clinical features of $\mathrm{AD}$ [106, 107]. In vitro studies revealed that apoE4-driven mitochondrial dysfunction is related to its isoform-specific binding to the F1 mitochondrial ATP synthase [108], as well as to an impaired ability to control the levels of reactive oxygen species and interactions with cytoskeletal proteins [70, 109-111].

\section{Neuroinflammation}

The association of activated microglia [112] and complement proteins [113] with brain $\mathrm{AD}$ lesions, as well the discovery that rheumatoid arthritis patients who were treated regularly with anti-inflammatory drugs are relatively spared from $\mathrm{AD}$, led to the proposition that neuroinflammation plays a role in the pathogenesis of $\mathrm{AD}$ [114]. This association between AD and neuroinflammation is further supported by recent genome-wide association studies that showed a marked association between $\mathrm{AD}$ and distinct immunity-associated genes such as $C L U$ and TREM2 $[115,116]$. Importantly, neuroinflammation is more pronounced in APOE4 carriers [117-119] and in corresponding animal model studies, including co-localization of apoE with microglia in the brain $[120,121]$, suggesting a role for apoE in the innate immune response in $\mathrm{AD}$ brain. This is corroborated by the finding that, in mice, following inflammatory stimulation, APOE4 carriers have an enhanced and prolonged neuroinflammatory response [47, 122-124]. This inflammation may be driven by the effects of apoE4 on microglial activation $[60,125]$ as well as by enhancing the levels of proinflammatory cytokines $[123,126]$. Alternatively, it has been suggested that the inflammatory effects of apoE4 may be related to miRNA146a, which is the primary miRNA in the brain. This suggestion stems from the finding that the levels of miRNA146a are higher in brains of AD patients than in the corresponding mouse model. It is suggested that elevated miRNA146a levels lead to an insufficient negative feedback regulation of inflammation, resulting in chronic inflammation [127, 128], yet the apoE isotype-specific effects remain poorly understood. However, in view of the uncertainty as to when in the course of the disease neuroinflammation is beneficial or toxic, the timing and choice of inflammatory molecule to be targeted for the treatment of $\mathrm{AD}$ and apoE4-related inflammation remain to be determined. Indeed, this issue may be the underlying cause for the lack of effectiveness of prospective nonsteroidal anti-inflammatory drug (NSAID) treatments [129]. A meta-analysis of numerous studies revealed no beneficial effect of NSAIDs on cognition and overall severity of AD [129]. Nevertheless, recent epidemiological data suggest that $A P O E 4$ carriers are better responders to NSAID treatment $[61,62,89]$. The mechanisms underlying this effect are not fully understood and may be related to the higher susceptibility of APOE4 carriers to inflammation and oxidative stress [130].

Nevertheless, it is clear that AD inflammation-related studies should be stratified according to the $A P O E$ genotype.

\section{Vascular integrity/function}

ApoE functions as a ligand for low-density lipoprotein (LDL) receptors and plays a role in lipid metabolism; it has been well described in the context of cardiovascular diseases [17, 131, 132]. Observations in AD brains using autopsy and imaging indicate cerebrovascular dysfunction, including disruption of microvascular integrity and reduced cerebral blood flow in addition to small vessel arteriosclerosis and amyloid angiopathy. These cerebrovascular changes are greater in APOE4 carriers when compared to non-carriers [133-135].

Several mechanisms have been proposed regarding the effects of apoE4 on cerebrovascular integrity, one of which is related to the accumulation of $A \beta$ in the $A D$ cerebral vasculature, a condition known as CAA. The 
prevalence of CAA is elevated in APOE4 carriers [21] and can severely disrupt the integrity of blood vessels, leading to hemodynamic disturbances and thrombosis as well as BBB dysfunction and microbleeds. Additionally, it has also been strongly associated with cognitive impairment in humans [136, 137].

Another molecule involved in vascular changes associated with $\mathrm{AD}$ pathophysiology and which is affected by apoE4 is fibrinogen. Both fibrinogen and fibrin accumulate in the $\mathrm{AD}$ neurovasculature [138], and through their interaction with $A \beta$, they lead to abnormality in fibrin clot formation, leading to a clot structure that is more resistant to enzymes responsible for degradation [139]. The accumulation of fibrin and fibrinogen along the vessel wall and in the tunica media is apoE isoform dependent (apoE4 $>$ apoE3) [140]. The mechanisms underlying this outcome merit further investigation.

Other than these direct effects of apoE on the vascular integrity, it is important to note that the apoE isoforms also affect the efficiency of the efflux of $A \beta$ across the BBB [141]. Accordingly, apoE4 disrupts the clearance of $A \beta$ through the BBB by shifting the efflux from fast LDL receptor-related protein 1 (LRP1)-dependent transcytosis to slow very low-density LDL receptor (VLDLR)-dependent transcytosis [141], resulting in poor clearance of $A \beta$ from the brain (which could explain the lower concentration of apoE in the CSF of APOE4 carriers).

\section{Insulin and VEGF signaling}

Recent advances suggest that both the insulin and the VEGF cascades are impaired in $\mathrm{AD}$ and are specifically affected by apoE4. Human and animal model studies revealed that $A D$ is associated with reduced insulin levels in the CSF and with insulin resistance [142], as well as with lower levels of the insulin receptor substrate IRS1 and higher levels of p-IRS1, which is a marker of brain insulin resistance [143-145]. Examination of the APOE genotype specificity of these effects revealed that brain insulin metabolism in AD is differentially affected by the various apoE isoforms [146], and that apoE4 impairs neuronal insulin signaling and insulin receptor trafficking in corresponding cellular and animal models [147-150]. Clinical trials of $\mathrm{AD}$ and mild cognitive impairment patients utilizing intranasal and other modes of insulin administration revealed general improvements in cognitive functions such as memory and attention [142, 151, 152]. Examination of the APOE genotype specificity of this effect revealed that this treatment was most effective in APOE4 carriers [153], although the lack of such specificity has also been reported [154].

VEGF, originally described as a key angiogenic factor, has recently been shown to play an important role in neurogenesis and neuroprotection and to affect neuronal plasticity and repair [155]. AD is associated with low serum VEGF levels [156], which are in turn associated with progressive loss of cognitive function [157]. Specific interactions between VEGF and apoE4 have been reported in both $\mathrm{AD}$ and mild cognitive impairment [158]. Animal model studies revealed that brain levels of VEGF and its receptor (VEGFR-2) were reduced in the hippocampus of apoE4-targeted replacement mice compared with the corresponding apoE3 mice and that upregulation of the levels of hippocampal VEGF utilizing a viral vector reversed the apoE4-driven accumulation of $\mathrm{A} \beta$ and hyperphosphorylated tau in hippocampal neurons and the associated synaptic and cognitive impairments [69].

\section{Synaptic plasticity}

Finally, another feature of $\mathrm{AD}$ that is probably linked very significantly to memory impairment and cognitive decline is synaptic failure. ApoE isoforms differentially regulate synaptic plasticity and repair. Clinical studies suggest that APOE4 carriers have lower levels of dendritic spine density in the hippocampus [159, 160], a finding that correlates well with the fact that apoE4 mice also have lower dendritic spine density and length compared with apoE3 mice [161-163] and suggests a different neuroprotective function of the isoforms. It is interesting to note that studies with 1-month-old mice revealed similar results, suggesting an early onset of apoE4-driven alteration of neuronal circuitry [164]. One of the key processes affected by apoE that leads to deficient synaptic plasticity is neurite (axon or dendritic) outgrowth. A large body of evidence has demonstrated that the apoE3 isoform promotes neurite outgrowth more effectively than apoE4, with apoE4 even inhibiting neurite outgrowth in some cases. Several mechanisms have been proposed. Firstly, the apoE receptor LRP1, which plays a major role in neurite outgrowth [165], was shown to be activated less effectively by apoE4 than by apoE3 [166]. Secondly, the activation of LRP1 by apoE is enhanced by the binding of apoE to heparin sulfate proteoglycan, a process that is more effective in apoE3 when compared to apoE4 [167]. In addition, the dynamics of actin polymerization, which plays an important role in neurite outgrowth and dendritic spine morphogenesis and can be stimulated via apoE receptor 2 (apoER2), is driven more effectively by apoE3 than by apoE4 $[168,169]$.

ApoE4 and apoE3 differ in their intracellular trafficking properties. Accordingly, following endocytosis, apoE3 readily undergoes retro-endocytosis, whereas apoE4 remains trapped in endosomes, suggesting that apoE4 clogs intracellular trafficking [170-172]. ApoE4 is associated with downregulating the levels of numerous receptors, including apoER $[55,173]$, as well as of growth factors and neurotransmitter receptors such as insulin [147, 148], VEGF [69], and N-methyl-D-aspartate (NMDA) receptors $[33,55]$, which could also play a role in impaired plasticity. 
In addition to direct neuron-related mechanisms, the isoform-specific effect of apoE4 on neurite outgrowth can also be mediated by controlling the rate of microglia activation and phagocytosis $[60,123,174,175]$ as well as the activation of the complement protein C1q, which is part of the brain's innate immune system [176].

\section{Summary}

As demonstrated, apoE is involved in several functions, many of which are potentially relevant to AD. Studies comparing the effects of apoE3 and apoE4 highlight the expected worse functions of apoE4. However, these studies were mainly performed in animals, of short-term duration, and qualitative rather than quantitative. Therefore, it is difficult to conclude which, if any, is relevant to the human form of the disease.

The relative contribution of the mechanisms discussed above on driving the effects of apoE4 on $\mathrm{AD}$ pathology and their use in providing a potential therapeutic target remains to be determined. In addition, it is important to note that the link between apoE4 and $\mathrm{AD}$ is more pronounced in female than in male APOE4 carriers, suggesting that specific sex-related hormones, or the lack thereof, may play a role in mediating the pathological effects of apoE4 [177, 178].

\section{Review of apoE4-targeted therapeutic approaches}

Human studies are only able to compare differences between carriers of the various haplotypes, and thus cannot determine whether the effects of apoE4 are toxic or merely less protective. Transgenic animals either lacking apoE altogether or carrying different human haplotypes can help answer this important question. Such studies revealed that important $\mathrm{AD}$ pathological effects, such as the accumulation of $A \beta$ in the brain, are significantly more pronounced in apoE4 than in apoE-deficient and apoE3 mice, suggesting that these effects are mediated via a gain of toxicity mechanism [23, 173, 179, 180]. However, other apoE4-driven phenotypes, such as astrocytic activation and synaptic loss, are similar to those observed in apoE-deficient mice [181], suggesting that they are driven by a loss of function mechanism of apoE4. Accordingly, since the levels of brain apoE4 in both $\mathrm{AD}$ and corresponding mice models are lower than those of apoE3 [182, 183], the effects of apoE4 could also be driven via a loss of function mechanism. It is thus possible that the effects of apoE4 in AD could be driven by multiple mechanisms, some of which could be driven by gain of toxicity and some by the loss of a protective function [117]. Since the relative contribution of such mechanisms is not known, it is not currently possible to recommend whether apoE4-related approaches should focus on counteracting apoE4 toxicity or on reversing an impaired protective mechanism. In view of this dilemma, we believe that apoE4-directed therapeutic approaches should focus primarily on the apoE4 molecule and assess both the efficacy of neutralizing the effects of apoE4, e.g., by removing apoE4 with antibodies, and of modifying the structure of the apoE4 molecule/ particle to render it similar to that of apoE3, e.g., by affecting the lipidation of apoE4. The answers obtained by these complementary approaches could then pave the way for the design of an AD-directed apoE4 therapy.

Below, we focus on the aspects of apoE4 for which therapeutic approaches are being developed. A more comprehensive review of the molecular mechanisms underlying the effects of apoE4 can be found in the available reviews $[17,55,62,64,184]$. We first focus on the $A P O E$ gene and the progress achieved by clustered regularly interspaced short palindromic repeats (CRISPR) gene editing on APOE. Approaches targeting the apoE4 protein, focusing on attempts to counteract its effects and modify its structure, are also discussed. Subsequently, the downstream approaches that focus on the interactions of apoE4 with target proteins, such as $\mathrm{A} \beta$ and apoE receptors and distinct signaling cascades, are reviewed. Finally, we focus on possible therapeutic targets related to the interaction of apoE4 with the vasculature and the inflammatory systems.

\section{Gene editing of APOE4 by CRISPR}

The conversion of the APOE4 gene to either APOE3 or $A P O E 2$ and the abolition of the concentration difference between them would lead to the ideal treatment, solving the crux of the apoE4 problem despite the incomplete understanding of the mechanisms underlying the effects of apoE4. Prior to the development of the gene-editing CRISPR technique, which enables the precise editing of genes [185], this would not have been possible. This technique is particularly suitable for the $A P O E$ gene, where the DNA coding for APOE4 differs from that of the more benign isoform for $\mathrm{AD}, A P O E 3$, by only one nucleotide (i.e., position 112 is arginine in $A P O E 4$ and cysteine in APOE3). Ideally, the CRISPR technique could be applied for converting the APOE4 allele to $A P O E 3$. However, it could also be applied in an $A P O E 4$-knockout paradigm which, by converting APOE3/APOE4 heterozygote mice to APOE3 homozygotes, would be expected to be protective if a toxic effect of apoE4 is assumed. CRISPR cell culture studies revealed the specific conversion of $A P O E 4$ to an $A P O E 3$ derivative [186], and the technique was applied to silence $A P O E 4$ without affecting the expression of apoE3 [187]. The latter approach is expected to therapeutically counteract the presumed gain of toxicity associated with apoE4. However, successful in vivo application of CRISPR to apoE4 mice has not yet been reported. Further, it is important to note that the CRISPR technique 
is in its infancy and data are still emerging regarding possible off-target gene editing and mosaicism, where not all copies of the target gene are edited.

\section{Approaches directed at the apoE4 protein Reversal of hypolipidation of apoE4}

The finding that $\mathrm{ABCA} 1$ plays a major role in the lipidation of apoE and that apoE4 is hypolipidated led to the suggestion that the pathological effects of apoE4 are related to its extent of lipidation and that it may be possible to counteract the pathological effects of apoE4 by increasing $A B C A 1$ activity. The expression of ABCA1 is regulated by LXR/RXR and can be activated in vivo by treatment with drugs such as bexarotene and 9-cis retinoic acid [96, 103, 188]. Treatment of apoE4 and apoE3 mice with these agents elevates the levels of ABCA1 in both groups; this was associated with a specific increase in the lipidation of brain apoE4 but with no effect on the lipidation of apoE3. The exact lipid composition of the apoE4 and apoE3 brain lipoprotein particles and the extent to which the composition is due to differences in the classes and levels of lipids associated with apoE4 remain to be determined. Additional studies utilizing apoE3 and apoE4 mice revealed that enhancing the expression of ABCA1 is associated with reversal of key apoE4 phenotypes such as the accumulation of $A \beta$ and hyperphosphorylated tau in hippocampal neurons as well as neuronal and synaptic impairments and cognitive deficits $[96,188]$. Similar results were obtained by an alternative approach in which ABCA1 was activated directly with an ABCA1 agonist $[96,103]$. These animal and cellular model studies, together with genetic studies that revealed $\mathrm{AD}$ to be associated with polymorphism in ABCA1 [189, 190] as well as with the related transporter ABCA7 [191], suggest that apoE4 is lipidated less effectively by $\mathrm{ABCA} 1$ and that the resulting hypolipidated apoE4 plays an important role in mediating the pathological effects of apoE4. The mechanisms underlying the reduced lipidation of apoE4 by $\mathrm{ABCA} 1$ remain to be determined. However, since the levels of ABCA1 in apoE4 and apoE3 mice are comparable [102, 103], it is likely that the hypolipidation of apoE4 is due to the conformation differences between those molecules that hamper the interaction of apoE4 with ABCA1. Taken together, these findings provide strong evidence that apoE4 is hypolipidated and that this may play an important role in driving the pathological effects of apoE4. Accordingly, ABCA1 is a promising AD apoE4-related therapeutic target; this calls for further translational studies directed at the development of novel and druggable brain permeating activators of ABCA1.

\section{Anti-apoE4 immunotherapy}

The underlying concept of apoE4 immunotherapy is similar to that employed in $A \beta$ and tau immunotherapy, namely to introduce or generate antibodies against these molecules in the periphery, which, following their permeation into the brain, can neutralize their target (this approach assumes a toxic effect of apoE4). Theoretically, the application of immunotherapy to apoE is faced by the problem that the levels of apoE in the periphery are approximately ten-fold higher than those in the brain [17] and that, consequently, anti-apoE antibodies could be titrated out in the periphery before reaching the brain. Contrary to this expectation, the Holtzman group has shown, utilizing amyloid precursor protein transgenic mice, that peripheral application of anti-mouse apoE can inhibit the accumulation of amyloid prior to plaque onset as well as decrease its accumulation after plaque formation [192, 193]. Although the mechanism underlying these central effects of the anti-apoE monoclonal antibodies and the reasons for them not being titrated out by peripheral apoE remain to be fully understood, these findings are of great importance and provide a proof-of-concept regarding the validity of anti-apoE4 immunotherapy as a therapeutic approach. This approach has now been extended to apoE4- and apoE3-targeted mice utilizing an antibody that reacts specifically with apoE4 [194]. This revealed that repeated intraperitoneal injection of mice with these antibodies results in their accumulation in the brain and in the formation of apoE/IgG complexes specifically in apoE4 mice. This was associated with the reversal of cognitive impairments in apoE4 mice as well as with the reversal of key AD-related and synaptic pathological effects of apoE4 [194]. These experiments, which were performed with apoE4 and apoE3 homozygous mice, are consistent with the suggestion that key pathological effects of apoE4 are mediated via a gain of toxicity mechanism.

\section{ApoE4 structural correctors}

ApoE4 assumes an intramolecular domain interaction that is specific to this apoE isoform and is believed to mediate its pathological effects [106]. Utilizing apoE molecules whose $\mathrm{N}$ - and $\mathrm{C}$-terminals were fluorescently labeled coupled with a high throughput screening approach, small druggable molecules that inhibit apoE4 domain interactions and counteract the key pathological effects of apoE4 in vitro were identified [195], thus providing a proof-of-principle that correcting the pathogenic conformation of apoE4 is a viable therapeutic approach for apoE-related processes in AD.

\section{ApoE degradation}

ApoE4 forms an intermediate molten globule conformation that renders it less stable than apoE3 and is associated with its $\mathrm{N}$ - and $\mathrm{C}$-terminal interaction as discussed above. This domain interaction renders apoE4 specifically susceptible to distinct proteases and leads to the 
generation of apoE4 carboxy terminal neurotoxic fragments [76, 77, 196, 197]. Since stress increases the neuronal production of apoE, it has been proposed that the increased production of intraneuronal apoE4 fragments under stressful conditions plays an important role in driving the pathological effects of apoE4 [76, 77, 196, 197]. Identification of the proteases involved in neuronal degradation of apoE4 and the development of inhibitors against them represent another approach for counteracting the effects of apoE4.

\section{Molecules interacting with apoE4 and downstream signaling}

Whereas the preceding sections centered on the $A P O E$ gene and protein as a therapeutic target, we shall now focus on molecules with which apoE interacts and on determining the extent to which the study of such interactions can lead to identifying novel therapeutic targets. Unlike apoE4 and its gene, the focus and relative weight of an apoE4 interactor is affected by a priori assumptions such as the relative contribution of the interactions of apoE4 with $A \beta$ and tau to the apoE4-driven pathology. Next, we highlight the therapeutic potential and limitations of the known apoE interactors.

\section{ApoE-directed anti-amyloid treatment}

$\mathrm{A} \beta$ deposition in the brains of normal controls and $\mathrm{AD}$ patients is higher in APOE4 carriers [198-202] and lower in $A P O E 2$ carriers compared with $A P O E 3$ carriers, and it appears earlier in healthy $A P O E 4$ carriers than in corresponding APOE4 non-carriers [203]. Animal model studies revealed that apoE affects several key steps in the amyloid cascade, including the aggregation, deposition, and clearance of $A \beta$, which, like in humans, has the isoform dependency of apoE4 $>$ apoE3 $>$ apoE2 [52, 53]. These findings led to the suggestion that important aspects of the pathological effects of apoE4 are mediated via its interaction with $A \beta$ and the amyloid cascade [184, 204], as well as to the development of apoE-related therapeutic strategies directed at reducing the amyloid load. This was first achieved in vitro utilizing a non-amyloidogenic $A \beta$-derived peptide that binds to apoE and mitigates $A \beta$ toxicity and fibril formation [205]. More recent in vivo experiments, utilizing antibodies that recognize both human apoE4 and apoE3 and that bind preferentially to non-lipidated apoE over lipidated apoE, revealed reduced $A \beta$ deposition in transgenic mice [206]. Reduction of amyloid pathology was also obtained using apoE antisense oligonucleotides [52]. The accepted findings that apoE4 and apoE3 bind differentially and directly to $A \beta[53]$ have recently been challenged by Verghese et al. [207], and it is thus possible that the cross-talk between apoE4 and $\mathrm{A} \beta$ may be indirect and mediated via a third molecule. Although these studies clearly show that the amyloid load can be decreased by lowering the level of apoE in the brain, the apoE isoform specificity of this effect and the extent to which it can alleviate the overall isoform-specific effects of apoE4 on brain $A \beta$ and other pathological effects of apoE4 remain to be determined.

\section{ApoE receptor-related approach}

Key physiological effects of apoE are mediated by the low-density lipoprotein receptor family, which includes the LDL receptor (LDLR), LRP1, the VLDLR, and the apoER2 as key players. The binding of apoE to these receptors is affected by the degree of lipidation of apoE such that non-lipidated apoE binds preferentially to LRP1 and VLDLR, whereas lipidated apoE binds more effectively to LDLR $[48,74,208]$. In addition, LRP1 and apoER2 are differentially affected by apoE4 and apoE3 $[55,209]$. It is of interest to note that the receptor-mediated effects of apoE4 are associated with increased internalization and subsequent degradation of numerous receptors, including NMDA, insulin, and VEGF receptors [33, 69, 147], as well as the amyloid precursor protein and apoER2 $[173,210]$. The diversity of receptors so affected by apoE4 suggests that apoE4 impairs a general receptor recycling mechanism. The pharmacology of the apoE receptors is not as rich and versatile as those of classical neurotransmitter receptors, and application of this receptor-directed pharmacology to counteract the effects of apoE4 is therefore not forthcoming. However, since one of the main effects of apoE4 is to lower the levels of apoE receptors such as apoER2 $[12,33,69]$, one possible therapeutic approach could be to correct this effect by increasing the expression of apoER2 utilizing appropriate vectors.

\section{ApoE mimetics}

An additional therapeutic approach is the use of apoE mimetic peptides. These small peptides, which either correspond to the receptor binding domain of apoE [211-213] or a distinct apoE domain, such as amphipathic helixes domains [213], markedly reduce neurodegeneration following brain insults [212, 214-217] and protect against $A \beta$ - and tau-driven pathology in transgenic mice and corresponding models [211-213]. The mechanism underlying the protective effects of the apoE mimetic peptides may be due to their anti-inflammatory effect. However, it should be noted that these peptides were protective following brain insults in both apoE4 and apoE3 mice [212]. Thus, assuming that these apoE mimetic peptides act and bind at the site recognized by apoE, this approach can be viewed as addressing the loss of function aspects of apoE4. 


\section{ApoE2-focused therapeutic approach}

The prevalence of apoE2 in $\mathrm{AD}$ subjects $(2.8-4.5 \%)$ is approximately two-fold lower than in the general population and it is associated with less pronounced brain pathology than that observed in non-apoE2 AD patients [218]. APOE2 heterozygosity is also associated with longevity [219] and reduced age-associated cognitive decline [220]. Accordingly, in neurodegenerative diseases that are associated with synaptic and neuronal loss, apoE2 is protective due to its ability to stimulate the repair of these processes. However, in age-related AMD, where excess angiogenesis in the retina is a key pathological feature, apoE2 seems to contribute to the pathology by stimulating plastic processes, which in this case mean enhanced neuro-vascularization. Several studies suggest that the brain pathological effects of apoE4 in targeted replacement mice can be counteracted by intracerebral injection of viral vectors expressing apoE2 [97, 221], suggesting a novel anti-apoE4 therapeutic approach [222]. Importantly, one of these studies also showed that apoE4 is hypolipidated relative to apoE3 and that apoE2 is hyperlipidated relative to apoE3 [97]. It is possible that apoE4 and apoE2 affect the same process, i.e., apoE lipidation, yet drive it in opposite directions. However, the possibility that apoE2 and apoE4 operate via different non-overlapping pathways with opposing physiological consequences cannot be excluded.

\section{ApoE4 and inflammation}

Several inflammation-related targets have been proposed. These include microglia, in which the recent identification of gene expression patterns related to different stages of microglial activation presents novel targets via which microglial activation can be modulated $[223,224]$ and which have been shown to be effective in neurodegeneration-related models [225]. These developments and the association of apoE4 with increased neuroinflammation (see Mitochondrial function section above) suggest that inflammation-related treatments could be particularly effective in APOE4 carriers. However, neuroinflammation is a double-edged sword, believed to be protective at early stages and pathological at subsequent chronic stages. The application of apoE4and AD-related immunotherapeutic strategies is thus expected to be dependent on the stage of the inflammatory reaction at which patients are treated. Furthermore, this may vary between different brain areas. New biomarkers that identify the stage and brain location of neuroinflammation are needed to resolve this issue.

\section{ApoE4 and vasculature}

Vascular risk factors such as hypertension, diabetes, and atherosclerosis increase the risk of $\mathrm{AD}[134,226]$. ApoE4 is associated with increased risk for vascular dementia and atherosclerosis $[227,228]$ as well as with impaired integrity of the vasculature and the BBB [229], suggesting that the contribution of apoE4 to AD may be driven, at least partially, by a vascular component. The identification of the molecules by which the AD-related vascular effects of apoE4 are mediated, and which could thus serve as an $\mathrm{AD}$-apoE4 vascular therapeutic target, remains currently unresolved [134]. However, since important aspects of vascular diseases can be treated pharmacologically and by lifestyle modifications [230], such approaches are expected to reduce the contribution of vascular and apoE4/vascular pathology to AD.

\section{ApoE4 as a transcription factor}

Whereas most of the suggested apoE4 pathological mechanisms are driven either extracellularly or via membrane transport and cytosolic processes, it has recently been suggested that apoE4 also undergoes nuclear translocation and that it binds specifically and with high affinity to numerous DNA sites [231]. Many of these sites are situated in promoter regions, suggesting that apoE4 could act as a transcription factor for a large number of varied genes, including autophagy and growth factor-related genes [232, 233]. Recent studies suggest that apoE4 localizes in the nucleus and that this process is related to specific proteolytic degradation of apoE4 [234]. These findings and the observation that apoE4 binds to the promoters of genes involved in a range of processes linked to aging and $\mathrm{AD}$ [235] led to the provocative suggestion that apoE4 may act as a transcription factor. Numerous key questions, such as how apoE escapes the endoplasmic reticulum and is trafficked to the nucleus and the impact of this mechanism relative to other pathological processes, remain to be determined. A key issue in this regard would be to determine the extent to which the pathological effects of apoE4 could be counteracted by blocking the translocation of apoE4 to the nucleus; obviously, these new observations need to be confirmed.

\section{Summary}

We described a number of apoE4-directed approaches, ranging from the $A P O E$ gene to the apoE protein and its interacting molecules, in both animal and cellular model systems. These experimental approaches (Fig. 1) have been developed to counteract the pathological effects of apoE4 in mice. At present, the landscape of human apoE4-targeted therapeutic trials is bare and it is hoped that advances in animal model studies will now provide the driving force for translating these observations from the laboratory to the clinic.

ApoE4-directed therapy will first be administered to APOE4 carriers who express early signs of the disease, 


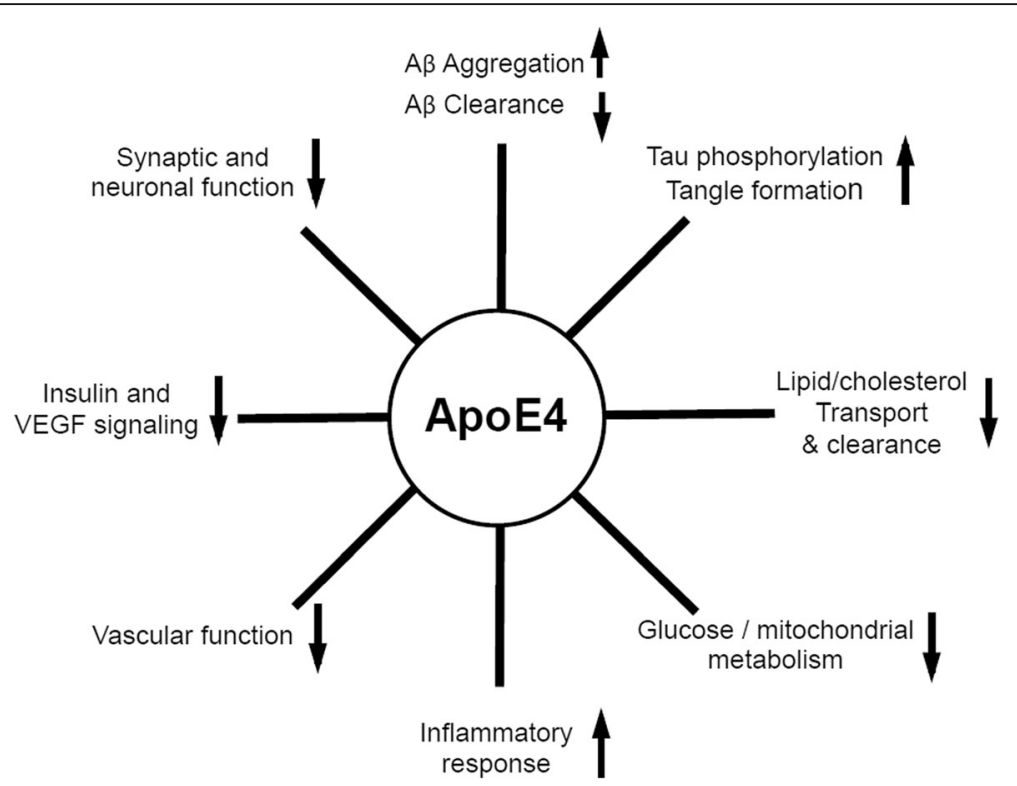

Fig. 1 Possible therapeutic approaches targeting apoE4

such as mild cognitive impairments, and early imaging changes such as hippocampal atrophy. Following a successful pursuit of this protocol, the effectivity of this treatment will be assessed when provided at more advanced disease stages. Prophylactic administration to APOE4 carriers could also be considered depending on the drug safety profile.

A schematic summary of all the proposed apoE-driven pathological mechanisms is presented in Fig. 2.

\section{Conclusion}

The upcoming development of specific therapies related to apoE4 raises several questions. First, will this therapy be curative rather than preventive? In other words, is it possible that $\mathrm{AD}$ patients who carry the APOE4 allele will improve when treated with the new therapy? It is possible that such treatment would slow the rate of decline in APOE4 carriers, yet it is likely that it would not entirely halter the neurodegenerative process. The

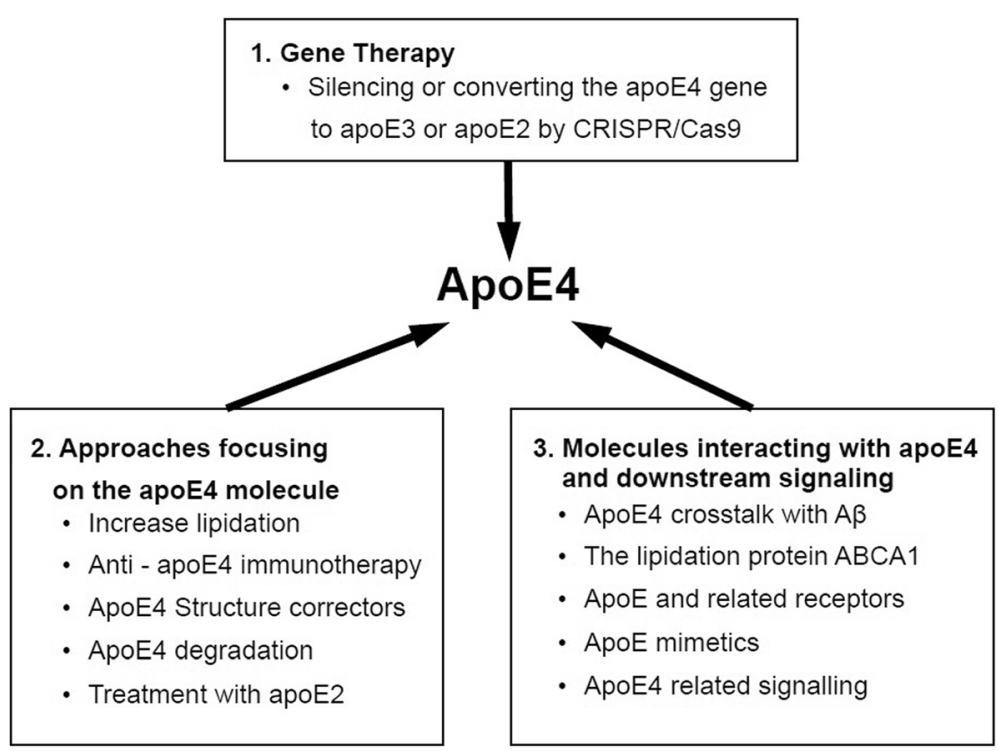

Fig. 2 Schematic presentation of the apoE4-driven mechanisms involved in AD pathology 
greatest potential of anti-apoE4 therapy therefore lies in delaying the onset and progression of dementia, rather than curing the disease. If such a therapy were to be initiated in non-demented individuals carrying the APOE4 allele, disease onset could be delayed by at least approximately 7 years per $A P O E 4$ allele; this intriguing possibility then poses the question of when therapy should commence. Another likely benefit of anti-apoE4 therapy is a reduction in the associated morbidities, e.g., cardiovascular disease, particularly coronary artery disease and impaired repair following head trauma, which are more common among APOE4 carriers [236].

\begin{abstract}
Abbreviations
AD: Alzheimer's disease; AMD: age-related macular degeneration; apoE: apolipoprotein $E_{;}$apoER: apolipoprotein $E$ receptor; $A B$ : amyloid beta; BBB: blood-brain barrier; CAA: cerebral amyloid angiopathy; CRISPR: clustered regularly interspaced short palindromic repeats; CSF: cerebrospinal fluid; DHA: docosoahexaenoic acid; DLB: dementia with Lewy bodies; EOAD: early-onset Alzheimer's disease; LDL: low-density lipoprotein; LDLR: LDL receptor; LOAD: late-onset Alzheimer's disease; LRP1: LDL receptor-related protein 1; NMDA: N-methyl-D-aspartate; NSAID: non-steroidal anti-inflammatory drug; VEGF: vascular endothelial growth factor; VLDLR: very low-density lipoprotein receptor
\end{abstract}

\section{Funding}

This work was supported in part by grants from the Israel Science Foundation (grant No. 794/17), from the Joseph Sagol Foundation, from the Harold Eleanore Foonberg Foundation, and from the Joseph K. and Inez Eichenbaum Foundation.

\section{Availability of data and materials}

All data generated or analysed during this study are included in this published article and its supplementary information files.

\section{Authors' contributions}

MS is the first author, and was a major contributor in writing the manuscripts. Both DM and AK contributed to the writing and proofreading of the manuscript. All authors have read and approved the final manuscript.

\section{Ethics approval and consent to participate}

Not applicable.

\section{Consent for publication}

Not applicable.

\section{Competing interests}

We confirm that we have read BMC's guidance on competing interests and none of the authors have any competing interests.

\section{Publisher's Note}

Springer Nature remains neutral with regard to jurisdictional claims in published maps and institutional affiliations.

\section{Author details}

'Department of Neurobiology, Sagol School of Neurosciences, The George S. Wise Faculty of Life Sciences, Tel Aviv University, Ramat Aviv, 6997801 Tel Aviv, Israel. ${ }^{2}$ Departments of Neurology and Pharmacology, Sackler Faculty of Medicine, Tel Aviv University, Tel Aviv, Israel.

Received: 28 October 2018 Accepted: 5 March 2019

Published online: 20 March 2019

\section{References}

1. Giacobini $\mathrm{E}$, Gold G. Alzheimer disease therapy--moving from amyloid- $\beta$ to tau. Nat Rev Neurol. 2013;9(12):677-86.
2. Iqbal K, Liu F, Gong C-X. Alzheimer disease therapeutics: focus on the disease and not just plaques and tangles. Biochem Pharmacol. 2014;88(4): 631-9.

3. Sasaguri $H$, Nilsson P, Hashimoto $S$, et al. APP mouse models for Alzheimer's disease preclinical studies. EMBO J. 2017;36(17):2473-87.

4. Iturria-Medina $Y$, Hachinski $V$, Evans AC. The vascular facet of late-onset Alzheimer's disease: an essential factor in a complex multifactorial disorder. Curr Opin Neurol. 2017;30(6):623-9.

5. Vijayan M, Kumar S, Bhatti JS, Reddy PH. Molecular links and biomarkers of stroke, vascular dementia, and Alzheimer's disease. Prog Mol Biol Transl Sci. 2017;146:95-126.

6. Naj AC, Schellenberg GD. Alzheimer's disease genetics consortium (ADGC). Genomic variants, genes, and pathways of Alzheimer's disease: an overview. Am J Med Genet B Neuropsychiatr Genet. 2017;174(1):5-26.

7. Apostolova LG, Risacher SL, Duran T, et al. Associations of the top 20 Alzheimer disease risk variants with brain amyloidosis. JAMA Neurol. 2018; 75(3):328-41.

8. Bis JC, Jian X, Kunkle BW, et al. Whole exome sequencing study identifies novel rare and common Alzheimer's-associated variants involved in immune response and transcriptional regulation. Mol Psychiatry. 2018. https://doi.org/10.1038/s41380-018-0112-7.

9. Ngandu T, Lehtisalo J, Solomon A, et al. A 2 year multidomain intervention of diet, exercise, cognitive training, and vascular risk monitoring versus control to prevent cognitive decline in at-risk elderly people (FINGER): a randomised controlled trial. Lancet. 2015;385(9984):2255-63.

10. Strittmatter WJ, Roses AD. Apolipoprotein E and Alzheimer's disease. Annu Rev Neurosci. 1996;19(1):53-77.

11. Michaelson DM. APOE $\varepsilon 4$ : the most prevalent yet understudied risk factor for Alzheimer's disease. Alzheimers Dement. 2014;10(6):861-8.

12. Holtzman DM, Herz J, Bu G. Apolipoprotein E and apolipoprotein E receptors: normal biology and roles in Alzheimer disease. Cold Spring Harb Perspect Med. 2012;2(3):a006312.

13. Di Battista AM, Heinsinger NM, Rebeck GW. Alzheimer's disease genetic risk factor APOE- $\varepsilon 4$ also affects normal brain function. Curr Alzheimer Res. 2016; 13(11):1200-7.

14. Martínez-Morillo E, Hansson O, Atagi Y, et al. Total apolipoprotein E levels and specific isoform composition in cerebrospinal fluid and plasma from Alzheimer's disease patients and controls. Acta Neuropathol. 2014;127(5):633-43.

15. Feingold KR, Grunfeld C. Introduction to lipids and lipoproteins. South Dartmouth: MDText.com, Inc.; 2000.

16. Getz GS, Reardon CA. Apoprotein E and reverse cholesterol transport. Int J Mol Sci. 2018;19(11):3479.

17. Mahley RW. Central nervous system lipoproteins: ApoE and regulation of cholesterol metabolism. Arterioscler Thromb Vasc Biol. 2016;36(7):1305-15.

18. Drummond E, Wisniewski T. Alzheimer's disease: experimental models and reality. Acta Neuropathol. 2017;133(2):155-75.

19. Roses AD. An inherited variable poly-T repeat genotype in TOMM40 in Alzheimer disease. Arch Neurol. 2010;67(5):536-41.

20. Chapman J, Korczyn AD, Karussis DM, Michaelson DM. The effects of APOE genotype on age at onset and progression of neurodegenerative diseases. Neurol. 2001;57(8):1482-5.

21. Rannikmae K, Kalaria RN, Greenberg SM, et al. APOE associations with severe CAA-associated vasculopathic changes: collaborative meta-analysis. J Neurol Neurosurg Psychiatry. 2014;85(3):300-5.

22. Tsuang $D$, Leverenz $J B$, Lopez $O L$, et al. APOE 4 increases risk for dementia in pure synucleinopathies. JAMA Neurol. 2013;70(2):223.

23. Shi Y, Yamada K, Liddelow SA, et al. ApoE4 markedly exacerbates taumediated neurodegeneration in a mouse model of tauopathy. Nature. 2017; 549(7673):523-7.

24. Treves TA, Bornstein NM, Chapman J, et al. APOE-epsilon 4 in patients with Alzheimer disease and vascular dementia. Alzheimer Dis Assoc Disord. 1996; 10(4):189-91.

25. Shin S, Walz KA, Archambault AS, et al. Apolipoprotein E mediation of neuro-inflammation in a murine model of multiple sclerosis. Neuroimmunol. 2014;271(1-2):8-17

26. Chapman J, Vinokurov S, Achiron A, et al. APOE genotype is a major predictor of long-term progression of disability in MS. Neurol. 2001;56(3): 312-6.

27. Liu B, Shen Y, Cen L, Tang Y. Apolipoprotein E gene polymorphism in a Chinese population with vascular dementia: a meta-analysis. Dement Geriatr Cogn Disord. 2012;33(2-3):96-103. 
28. Li L, Bao Y, He S, et al. The association between apolipoprotein $E$ and functional outcome after traumatic brain injury. Medicine (Baltimore). 2015; 94(46):e2028.

29. Kassam I, Gagnon F, Cusimano MD. Association of the APOE- $\varepsilon 4$ allele with outcome of traumatic brain injury in children and youth: a meta-analysis and meta-regression. J Neurol Neurosurg Psychiatry. 2016;87(4):433-40.

30. Xiying M, Wenbo W, Wangyi F, Qinghuai L. Association of apolipoprotein E polymorphisms with age-related macular degeneration subtypes: an updated systematic review and meta-analysis. Arch Med Res. 2017;48(4):370-7.

31. Espina $M$, Arcinue $C A, M a$ F, et al. Outer retinal tubulations response to antiVEGF treatment. Br J Ophthalmol. 2016;100(6):819-23.

32. Koch G, Di Lorenzo F, Loizzo S, et al. CSF tau is associated with impaired cortical plasticity, cognitive decline and astrocyte survival only in APOE4positive Alzheimer's disease. Sci Rep. 2017;7(1):13728.

33. Chen $Y$, Durakoglugil MS, Xian $X$, Herz J. ApoE4 reduces glutamate receptor function and synaptic plasticity by selectively impairing ApoE receptor recycling. Proc Natl Acad Sci U S A. 2010;107(26):12011-6.

34. Teter B. ApoE-dependent plasticity in Alzheimer's disease. J Mol Neurosci. 2004;23(3):167-79.

35. Chung W-S, Verghese PB, Chakraborty C, et al. Novel allele-dependent role for APOE in controlling the rate of synapse pruning by astrocytes. Proc Natl Acad Sci. 2016;113(36):10186-91.

36. Masuda T, Shimazawa M, Hashimoto $Y$, et al. Apolipoprotein E2 and E3, but not E4, promote retinal pathologic neovascularization. Invest Ophthalmol Vis Sci. 2017;58(2):1208-17.

37. Mishra A, Ferrari R, Heutink $P$, et al. Gene-based association studies report genetic links for clinical subtypes of frontotemporal dementia. Brain. 2017; 140(5):1437-46.

38. Stevens M, van Duijn CM, de Knijff P, et al. Apolipoprotein E gene and sporadic frontal lobe dementia. Neurol. 1997;48(6):1526-9.

39. Hofman A, Ott A, Breteler MM, et al. Atherosclerosis, apolipoprotein E, and prevalence of dementia and Alzheimer's disease in the Rotterdam study. Lancet. 1997;349(9046):151-4.

40. McCarron MO, Delong D, Alberts MJ. APOE genotype as a risk factor for ischemic cerebrovascular disease: a meta-analysis. Neurol. 1999;53(6):1308-11.

41. Newman MF, Laskowitz DT, White WD, et al. Apolipoprotein E polymorphisms and age at first coronary artery bypass graft. Anesth Analg 2001:92(4):824-9.

42. Schneider JA, Bienias JL, Wilson RS, et al. The apolipoprotein E epsilon4 allele increases the odds of chronic cerebral infarction [corrected] detected at autopsy in older persons. Stroke. 2005;36(5):954-9.

43. Chapman J, Wang N, Treves TA, Korczyn AD, Bornstein NM. ACE, MTHFR, factor $V$ Leiden, and APOE polymorphisms in patients with vascular and Alzheimer's dementia. Stroke. 1998;29(7):1401-4.

44. Sudlow C, Martínez González NA, Kim J, Clark C. Does apolipoprotein E genotype influence the risk of ischemic stroke, intracerebral hemorrhage, or subarachnoid hemorrhage? Systematic review and meta-analyses of 31 studies among 5961 cases and 17,965 controls. Stroke. 2006;37(2):364-70.

45. Poels MMF, Vernooij MW, Ikram MA, et al. Prevalence and risk factors of cerebral microbleeds: an update of the Rotterdam scan study. Stroke. 2010; 41(10 Suppl):S103-6.

46. Hanson AJ, Craft S, Banks WA. The APOE genotype: modification of therapeutic responses in Alzheimer's disease. Curr Pharm Des. 2015;21(1): 114-20

47. Dorey E, Chang N, Liu QY, Yang Z, Zhang W. Apolipoprotein E, amyloidbeta, and neuroinflammation in Alzheimer's disease. Neurosci Bull. 2014; 30(2):317-30

48. Kanekiyo $T, X u H, B u$ G. ApoE and Aß in Alzheimer's disease: accidental encounters or partners? Neuron. 2014;81(4):740-54

49. Kok E, Haikonen S, Luoto T, et al. Apolipoprotein E-dependent accumulation of Alzheimer disease-related lesions begins in middle age. Ann Neurol. 2009;65(6):650-7.

50. Polvikoski T, Sulkava R, Haltia M, et al. Apolipoprotein E, dementia, and cortical deposition of beta-amyloid protein. N Engl J Med. 1995;333(19):1242-7.

51. Shinohara M, Petersen RC, Dickson DW, Bu G. Brain regional correlation of amyloid- $\beta$ with synapses and apolipoprotein $E$ in non-demented individuals: potential mechanisms underlying regional vulnerability to amyloid- $\beta$ accumulation. Acta Neuropathol. 2013;125(4):535-47.

52. Huynh T-PV, Davis AA, Ulrich JD, Holtzman DM. Apolipoprotein E and Alzheimer's disease: the influence of apolipoprotein $E$ on amyloid- $\beta$ and other amyloidogenic proteins. J Lipid Res. 2017;58(5):824-36.
53. Tai LM, Bilousova $T$, Jungbauer $L$, et al. Levels of soluble apolipoprotein $E /$ amyloid- $\beta$ ( $A \beta$ ) complex are reduced and oligomeric $A \beta$ increased with APOE4 and Alzheimer disease in a transgenic mouse model and human samples. J Biol Chem. 2013;288(8):5914-26.

54. Liu S, Park S, Allington $G$, et al. Targeting apolipoprotein E/amyloid $\beta$ binding by peptoid CPO_AB17-21 P ameliorates Alzheimer's disease related pathology and cognitive decline. Sci Rep. 2017;7(1):8009.

55. Lane-Donovan C, Herz J. The ApoE receptors Vldlr and Apoer2 in central nervous system function and disease. J Lipid Res. 2017;58(6):1036-43.

56. Du J, Chang J, Guo S, Zhang Q, Wang Z. ApoE 4 reduces the expression of Abeta degrading enzyme IDE by activating the NMDA receptor in hippocampal neurons. Neurosci Lett. 2009;464(2):140-5.

57. Nielsen HM, Mulder SD, Beliën JAM, et al. Astrocytic AB1-42 uptake is determined by $A \beta$-aggregation state and the presence of amyloidassociated proteins. Glia. 2010;58(10):1235-46.

58. Jiang $Q$, Lee CYD, Mandrekar S, et al. ApoE promotes the proteolytic degradation of AB. Neuron. 2008;58(5):681-93.

59. Zekonyte J, Sakai K, Nicoll JAR, Weller RO, Carare RO. Quantification of molecular interactions between $\mathrm{ApoE}$, amyloid-beta $(\mathrm{AB})$ and laminin: relevance to accumulation of $A \beta$ in Alzheimer's disease. Biochim Biophys Acta. 2016:1862(5):1047-53.

60. Rodriguez GA, Tai LM, LaDu MJ, Rebeck GW. Human APOE4 increases microglia reactivity at $A \beta$ plaques in a mouse model of $A \beta$ deposition. J Neuroinflammation. 2014;11(1):111

61. Kim J, Yoon H, Basak J, Kim J. Apolipoprotein E in synaptic plasticity and Alzheimer's disease: potential cellular and molecular mechanisms. Mol Cell. 2014;37(11):767-76.

62. Liao F, Yoon H, Kim J. Apolipoprotein E metabolism and functions in brain and its role in Alzheimer's disease. Curr Opin Lipidol. 2017;28(1):60-7.

63. Poirier J, Miron J, Picard C, et al. Apolipoprotein E and lipid homeostasis in the etiology and treatment of sporadic Alzheimer's disease. Neurobiol Aging. 2014;35(Suppl 2):S3-10.

64. Tai LM, Ghura S, Koster KP, et al. APOE-modulated A $\beta$-induced neuroinflammation in Alzheimer's disease: current landscape, novel data, and future perspective. J Neurochem. 2015;133(4):465-88.

65. Cramer PE, Cirrito JR, Wesson DW, et al. ApoE-directed therapeutics rapidly clear $\beta$-amyloid and reverse deficits in AD mouse models. Science. 2012 335(6075):1503-6.

66. Hampel H, Blennow K, Shaw LM, et al. Total and phosphorylated tau protein as biological markers of Alzheimer's disease. Exp Gerontol. 2010;45(1):30-40.

67. Damoiseaux JS, Seeley WW, Zhou J, et al. Gender modulates the APOE $\varepsilon 4$ effect in healthy older adults: convergent evidence from functional brain connectivity and spinal fluid tau levels. J Neurosci. 2012;32(24):8254-62.

68. Leoni $\mathrm{V}$. The effect of apolipoprotein $\mathrm{E}$ (ApoE) genotype on biomarkers of amyloidogenesis, tau pathology and neurodegeneration in Alzheimer's disease. Clin Chem Lab Med. 2011;49(3):375-83.

69. Salomon-Zimri S, Glat MJ, Barhum Y, et al. Reversal of ApoE4-driven brain pathology by vascular endothelial growth factor treatment. J Alzheimers Dis. 2016:53(4):1443-58.

70. Liraz O, Boehm-Cagan A, Michaelson DM. ApoE4 induces A 342 , tau, and neuronal pathology in the hippocampus of young targeted replacement apoE4 mice. Mol Neurodegener. 2013;8(1):16.

71. Genis I, Gordon I, Sehayek E, Michaelson DM. Phosphorylation of tau in apolipoprotein E-deficient mice. Neurosci Lett. 1995;199(1):5-8.

72. Tesseur I, Van Dorpe J, Spittaels K, et al. Expression of human apolipoprotein E4 in neurons causes hyperphosphorylation of protein tau in the brains of transgenic mice. Am J Pathol. 2000;156(3):951-64.

73. Mannix R, Meehan WP, Mandeville J, et al. Clinical correlates in an experimental model of repetitive mild brain injury. Ann Neurol. 2013;74(1):65-75.

74. Bu G. Apolipoprotein E and its receptors in Alzheimer's disease: pathways, pathogenesis and therapy. Nat Rev Neurosci. 2009;10(5):333-44.

75. Dubnikov T, Cohen E. The emerging roles of early protein folding events in the secretory pathway in the development of neurodegenerative maladies. Front Neurosci. 2017:11:48.

76. Harris FM, Brecht WJ, Xu Q, Mahley RW, Huang Y. Increased tau phosphorylation in apolipoprotein E4 transgenic mice is associated with activation of extracellular signal-regulated kinase. J Biol Chem. 2004;279(43): 44795-801.

77. Brecht WJ, Harris FM, Chang S, et al. Neuron-specific apolipoprotein E4 proteolysis is associated with increased tau phosphorylation in brains of transgenic mice. J Neurosci. 2004;24(10):2527-34. 
78. Harris FM, Brecht WJ, Xu Q, Mahley RW, Huang Y. Increased tau phosphorylation in apolipoprotein E4 transgenic mice is associated with activation of extracellular signal-regulated kinase: modulation by zinc. J Biol Chem. 2004:279(43):44795-801.

79. Wennberg AM, Tosakulwong N, Lesnick TG, et al. Association of apolipoprotein $\mathrm{E} \varepsilon 4$ with transactive response DNA-binding protein 43 . JAMA Neurol. 2018;75(11):1347-54.

80. Yang H-S, Yu L, White CC, et al. Evaluation of TDP-43 proteinopathy and hippocampal sclerosis in relation to APOE $\varepsilon 4$ haplotype status: a community-based cohort study. Lancet Neurol. 2018;17(9):773-81.

81. Robinson JL, Lee EB, Xie SX, et al. Neurodegenerative disease concomitant proteinopathies are prevalent, age-related and APOE4-associated. Brain. 2018;141(7):2181-93.

82. Lemke S, Vicini J, Su H. Dietary intake of stearidonic acid - enriched soybean oil increases the omega-3 index : randomized, double-blind clinical study of efficacy and safety. Am J Clin Nutr. 2010;92(4):766-75.

83. Belkouch $M$, Hachem $M$, Elgot $A$, et al. The pleiotropic effects of omega-3 docosahexaenoic acid on the hallmarks of Alzheimer's disease. J Nutr Biochem. 2016;38:1-11.

84. Nock TG, Chouinard-Watkins R, Plourde M. Carriers of an apolipoprotein E epsilon 4 allele are more vulnerable to a dietary deficiency in omega-3 fatty acids and cognitive decline. Biochim Biophys Acta Mol Cell Biol Lipids. 2017; 1862(10 Pt A):1068-78

85. Yassine HN, Croteau E, Rawat V, et al. DHA brain uptake and APOE4 status: a PET study with [1-11C]-DHA. Alzheimers Res Ther. 2017;9(1):23.

86. Salem N, Vandal M, Calon F. The benefit of docosahexaenoic acid for the adult brain in aging and dementia. Prostaglandins Leukot Essent Fat Acids. 2015;92:15-22

87. Kariv-Inbal Z, Yacobson S, Berkecz R, et al. The isoform-specific pathological effects of apoE4 in vivo are prevented by a fish oil (DHA) diet and are modified by cholesterol. J Alzheimers Dis. 2012;28(3):667-83.

88. Yassine HN, Braskie MN, Mack WJ, et al. Association of docosahexaenoic acid supplementation with Alzheimer disease stage in apolipoprotein E $\varepsilon 4$ carriers. JAMA Neurol. 2017;74(3):339.

89. Harris JR, Milton NGN. Cholesterol in Alzheimer's disease and other amyloidogenic disorders. Subcell Biochem. 2010;51:47-75.

90. Zhu L, Zhong M, Elder GA, et al. Phospholipid dysregulation contributes to ApoE4-associated cognitive deficits in Alzheimer's disease pathogenesis. Proc Natl Acad Sci U S A. 2015;112(38):11965-70.

91. Grimm MOW, Zimmer VC, Lehmann J, Grimm HS, Hartmann T. The impact of cholesterol, DHA, and sphingolipids on Alzheimer's disease. Biomed Res Int. 2013;2013:814390.

92. Zinser EG, Hartmann T, Grimm MOW. Amyloid beta-protein and lipid metabolism. Biochim Biophys Acta Biomembr. 2007;1768(8):1991-2001.

93. Vestergaard M, Hamada T, Morita M, Takagi M. Cholesterol, lipids, amyloid beta, and Alzheimers. Curr Alzheimer Res. 2010;7(3):262-70.

94. Bangen K, Beiser A, Delano-Wood L, et al. APOE genotype modifies the relationship between midlife vascular risk factors and later cognitive decline. J Stroke Cerebrovasc Dis. 2013;22(8):1361-9.

95. Anstey KJ, Lipnicki DM, Low L-F. Cholesterol as a risk factor for dementia and cognitive decline: a systematic review of prospective studies with meta-analysis. Am J Geriatr Psychiatry. 2008;16(5):343-54.

96. Boehm-Cagan A, Michaelson DM. Reversal of apoE4-driven brain pathology and behavioral deficits by bexarotene. J Neurosci. 2014; 34(21):7293-301.

97. Hu J, Liu C-C, Chen X-F, et al. Opposing effects of viral mediated brain expression of apolipoprotein E2 (apoE2) and apoE4 on apoE lipidation and $A \beta$ metabolism in apoE4-targeted replacement mice. Mol Neurodegener. 2015;10(1):6.

98. Yassine HN, Rawat V, Mack WJ, et al. The effect of APOE genotype on the delivery of DHA to cerebrospinal fluid in Alzheimer's disease. Alzheimers Res Ther. 2016;8(1):25.

99. Heinsinger NM, Gachechiladze MA, Rebeck GW. Apolipoprotein E genotype affects size of ApoE complexes in cerebrospinal fluid. J Neuropathol Exp Neurol. 2016;75(10):918-24.

100. Kim WS, Weickert CS, Garner B. Role of ATP-binding cassette transporters in brain lipid transport and neurological disease. J Neurochem. 2008;104(5): 1145-66.

101. Wahrle $S E$, Jiang $H$, Parsadanian $M$, et al. ABCA1 is required for normal central nervous system ApoE levels and for lipidation of astrocyte-secreted apoE. J Biol Chem. 2004;279(39):40987-93.
102. Fitz NF, Cronican AA, Saleem M, et al. Abca1 deficiency affects Alzheimer's disease-like phenotype in human ApoE4 but not in ApoE3-targeted replacement mice. J Neurosci. 2012;32(38):13125-36.

103. Boehm-Cagan A, Bar R, Liraz $O$, et al. ABCA1 agonist reverses the ApoE4-driven cognitive and brain pathologies. J Alzheimers Dis. 2016; 54(3):1219-33.

104. Boehm-Cagan A, Bar R, Harats D, et al. Differential effects of apoE4 and activation of ABCA1 on brain and plasma lipoproteins. PLoS One. 2016; 11(11):e0166195.

105. Chen Z, Zhong C. Decoding Alzheimer's disease from perturbed cerebral glucose metabolism: implications for diagnostic and therapeutic strategies. Prog Neurobiol. 2013;108:21-43.

106. Chen HK, Ji ZS, Dodson SE, et al. Apolipoprotein E4 domain interaction mediates detrimental effects on mitochondria and is a potential therapeutic target for alzheimer disease. J Biol Chem. 2011;286(7):5215-21.

107. Chang S, ran Ma T, Miranda RD, et al. Lipid- and receptor-binding regions of apolipoprotein E4 fragments act in concert to cause mitochondrial dysfunction and neurotoxicity. Proc Natl Acad Sci U S A. 2005;102(51): 18694-9.

108. Wolf AB, Caselli RJ, Reiman EM, Valla J. APOE and neuroenergetics: an emerging paradigm in Alzheimer's disease. Neurobiol Aging. 2013;34(4): 1007-17.

109. Zhou M, Huang T, Collins N, et al. APOE4 induces site-specific tau phosphorylation through calpain-CDK5 signaling pathway in EFAD-Tg mice. Curr Alzheimer Res. 2016;13(9):1048-55.

110. Friedland-Leuner K, Stockburger C, Denzer I, Eckert GP, Müller WE. Mitochondrial dysfunction: cause and consequence of Alzheimer's disease. Prog Mol Biol Transl Sci. 2014;127:183-210.

111. Tesseur I, Van Dorpe J, Bruynseels K, et al. Prominent axonopathy and disruption of axonal transport in transgenic mice expressing human apolipoprotein E4 in neurons of brain and spinal cord. Am J Pathol. 2000; 157(5):1495-510.

112. Clayton KA, Van Enoo AA, Ikezu T. Alzheimer's disease: the role of microglia in brain homeostasis and proteopathy. Front Neurosci. 2017;11:680.

113. Kolev MV, Ruseva MM, Harris CL, Morgan BP, Donev RM. Implication of complement system and its regulators in Alzheimer's disease. Curr Neuropharmacol. 2009;7(1):1-8.

114. McGeer PL, Rogers J, McGeer EG. Inflammation, antiinflammatory agents, and Alzheimer's disease: the last 22 years. J Alzheimers Dis. 2016;54(3):853-7.

115. Zhang S, Li X, Ma G, et al. CLU rs9331888 polymorphism contributes to Alzheimer's disease susceptibility in Caucasian but not east Asian populations. Mol Neurobiol. 2016;53(3):1446-51.

116. Colonna M, Wang Y. TREM2 variants: new keys to decipher Alzheimer disease pathogenesis. Nat Rev Neurosci. 2016;17(4):201-7.

117. Liu C-C, Kanekiyo T, Xu H, Bu G, Bu G. Apolipoprotein E and Alzheimer disease: risk, mechanisms and therapy. Nat Rev Neurol. 2013;9(2):106-18

118. Reale M, Kamal MA, Velluto L, et al. Relationship between inflammatory mediators, Abeta levels and ApoE genotype in Alzheimer disease. Curr Alzheimer Res. 2012;9(4):447-57.

119. Gorelick PB. Role of inflammation in cognitive impairment: results of observational epidemiological studies and clinical trials. Ann N Y Acad Sci. 2010:1207(1):155-62

120. Härtig W, Brückner G, Schmidt C, et al. Co-localization of beta-amyloid peptides, apolipoprotein $\mathrm{E}$ and glial markers in senile plaques in the prefrontal cortex of old rhesus monkeys. Brain Res. 1997;751(2):315-22.

121. Thanopoulou K, Fragkouli A, Stylianopoulou F, Georgopoulos S. Scavenger receptor class B type I (SR-BI) regulates perivascular macrophages and modifies amyloid pathology in an Alzheimer mouse model. Proc Natl Acad Sci U S A. 2010;107(48):20816-21.

122. Du Z, Jia H, Liu J, Zhao X, Xu W. Effects of three hydrogen-rich liquids on hemorrhagic shock in rats. J Surg Res. 2015;193(1):377-82.

123. Ophir G, Amariglio N, Jacob-Hirsch J, et al. Apolipoprotein E4 enhances brain inflammation by modulation of the NF-kappaB signaling cascade. Neurobiol Dis. 2005;20(3):709-18.

124. Cash JG, Kuhel DG, Basford JE, et al. Apolipoprotein E4 impairs macrophage efferocytosis and potentiates apoptosis by accelerating endoplasmic reticulum stress. J Biol Chem. 2012;287(33):27876-84.

125. Li X, Montine KS, Keene CD, Montine TJ. Different mechanisms of apolipoprotein $\mathrm{E}$ isoform-dependent modulation of prostaglandin E2 production and triggering receptor expressed on myeloid cells 2 (TREM2) 
expression after innate immune activation of microglia. FASEB J. 2015;29(5): 1754-62.

126. Fan Y-Y, Cai Q-L, Gao Z-Y, et al. APOE $\varepsilon 4$ allele elevates the expressions of inflammatory factors and promotes Alzheimer's disease progression: a comparative study based on Han and she populations in the Wenzhou area. Brain Res Bull. 2017;132:39-43.

127. Teter B, LaDu MJ, Sullivan PM, Frautschy SA, Cole GM. Apolipoprotein E isotype-dependent modulation of microRNA-146a in plasma and brain. Neuroreport. 2016;23(7):829-38.

128. Lukiw WJ, Zhao Y, Cui JG. An NF-kappaB-sensitive micro RNA-146amediated inflammatory circuit in Alzheimer disease and in stressed human brain cells. J Biol Chem. 2008;283(46):31315-22.

129. Miguel-Álvarez M, Santos-Lozano A, Sanchis-Gomar F, et al. Nonsteroidal anti-inflammatory drugs as a treatment for Alzheimer's disease: a systematic review and meta-analysis of treatment effect. Drugs Aging. 2015;32(2):139-47.

130. Heneka MT, Carson MJ, El Khoury J, et al. Neuroinflammation in Alzheimer's disease. Lancet Neurol. 2015;14(4):388-405.

131. Raffai RL, Weisgraber KH. Cholesterol: from heart attacks to Alzheimer's disease. J Lipid Res. 2003;44(8):1423-30.

132. Liehn EA, Ponomariov V, Diaconu R, et al. Apolipoprotein E in cardiovascular diseases: novel aspects of an old-fashioned enigma. Arch Med Res. 2018. https://doi.org/10.1016/j.arcmed.2018.08.008.

133. Mielke MM, Leoutsakos J-M, Tschanz JT, et al. Interaction between vascular factors and the APOE $\varepsilon 4$ allele in predicting rate of progression in Alzheimer's disease. J Alzheimers Dis. 2011;26(1):127-34.

134. Bell RD. The imbalance of vascular molecules in Alzheimer's disease. J Alzheimers Dis. 2012;32(3):699-709.

135. Tai LM, Thomas R, Marottoli FM, et al. The role of APOE in cerebrovascular dysfunction. Acta Neuropathol. 2016;131(5):709-23.

136. Saito S, Yamamoto $Y$, Ihara M. Mild cognitive impairment: at the crossroad of neurodegeneration and vascular dysfunction. Curr Alzheimer Res. 2015; 12(6):507-12.

137. Schöberl F, Eren OE, Wollenweber FA, Kraus T, Kellert L. Sporadic cerebral amyloid angiopathy: an overview with clinical cases. Fortschr Neurol Psychiatr. 2016;84(9):534-41.

138. Cortes-Canteli M, Zamolodchikov D, Ahn HJ, Strickland S, Norris EH. Fibrinogen and altered hemostasis in Alzheimer's disease. J Alzheimers Dis. 2012;32(3):599-608.

139. Ahn HJ, Chen Z-L, Zamolodchikov D, Norris EH, Strickland S. Interactions of $\beta$-amyloid peptide with fibrinogen and coagulation factor XII may contribute to Alzheimer's disease. Curr Opin Hematol. 2017;24(5):427-31.

140. Hultman K, Strickland S, Norris EH. The APOE $\varepsilon 4 / \varepsilon 4$ genotype potentiates vascular fibrin(ogen) deposition in amyloid-laden vessels in the brains of Alzheimer's disease patients. J Cereb Blood Flow Metab. 2013;33(8):1251-8.

141. Deane R, Sagare A, Hamm K, et al. apoE isoform-specific disruption of amyloid beta peptide clearance from mouse brain. J Clin Invest. 2008; 118(12):4002-13.

142. Stanley M, Macauley SL, Holtzman DM. Changes in insulin and insulin signaling in Alzheimer's disease: cause or consequence? J Exp Med. 2016; 213(8):1375-85.

143. Steen E, Terry BM, Rivera EJ, et al. Impaired insulin and insulin-like growth factor expression and signaling mechanisms in Alzheimer's disease--is this type 3 diabetes? J Alzheimers Dis. 2005;7(1):63-80.

144. Yarchoan M, Toledo JB, Lee EB, et al. Abnormal serine phosphorylation of insulin receptor substrate 1 is associated with tau pathology in Alzheimer's disease and tauopathies. Acta Neuropathol. 2014;128(5):679-89.

145. Moloney AM, Griffin RJ, Timmons S, et al. Defects in IGF-1 receptor, insulin receptor and IRS-1/2 in Alzheimer's disease indicate possible resistance to IGF-1 and insulin signalling. Neurobiol Aging. 2010;31(2):224-43.

146. Keeney JT-R, Ibrahimi S, Zhao L. Human ApoE isoforms differentially modulate glucose and amyloid metabolic pathways in female brain: evidence of the mechanism of neuroprotection by ApoE2 and implications for Alzheimer's disease prevention and early intervention. J Alzheimers Dis. 2015;48(2):411-24.

147. Zhao N, Liu C-C, Van Ingelgom AJ, et al. Apolipoprotein E4 impairs neuronal insulin signaling by trapping insulin receptor in the endosomes. Neuron. 2017;96(1):115-29.e5

148. Traversy M-T, Vandal M, Tremblay C, et al. Altered cerebral insulin response in transgenic mice expressing the epsilon-4 allele of the human apolipoprotein E gene. Psychoneuroendocrinol. 2017;77:203-10.
149. Chan ES, Chen C, Cole GM, Wong B-S. Differential interaction of apolipoprotein-E isoforms with insulin receptors modulates brain insulin signaling in mutant human amyloid precursor protein transgenic mice. Sci Rep. 2015;5(1):13842

150. Ong Q-R, Chan ES, Lim M-L, Cole GM, Wong B-S. Reduced phosphorylation of brain insulin receptor substrate and Akt proteins in apolipoprotein-E4 targeted replacement mice. Sci Rep. 2014;4(1):3754.

151. Freiherr J, Hallschmid M, Frey WH, et al. Intranasal insulin as a treatment for Alzheimer's disease: a review of basic research and clinical evidence. CNS Drugs. 2013;27(7):505-14.

152. Avgerinos Kl, Kalaitzidis G, Malli A, et al. Intranasal insulin in Alzheimer's dementia or mild cognitive impairment: a systematic review. J Neurol. 2018; 265(7):1497-510.

153. Claxton A, Baker LD, Hanson A, et al. Long-acting intranasal insulin detemir improves cognition for adults with mild cognitive impairment or early-stage Alzheimer's disease dementia. J Alzheimers Dis. 2015;44(3):897-906.

154. Reger MA, Watson GS, Green PS, et al. Intranasal insulin administration dose-dependently modulates verbal memory and plasma amyloid-beta in memory-impaired older adults. J Alzheimers Dis. 2008;13(3):323-31.

155. Licht T, Keshet E. Delineating multiple functions of VEGF-A in the adult brain. Cell Mol Life Sci. 2013;70(10):1727-37.

156. Mateo I, Llorca J, Infante J, et al. Low serum VEGF levels are associated with Alzheimer's disease. Acta Neurol Scand. 2007;116(1):56-8.

157. Tang H, Mao X, Xie L, Greenberg DA, Jin K. Expression level of vascular endothelial growth factor in hippocampus is associated with cognitive impairment in patients with Alzheimer's disease. Neurobiol Aging. 2013; 34(5):1412-5.

158. Chiappelli M, Borroni B, Archetti S, et al. VEGF gene and phenotype relation with Alzheimer's disease and mild cognitive impairment. Rejuvenation Res. 2006:9(4):485-93.

159. Boros BD, Greathouse KM, Gentry EG, et al. Dendritic spines provide cognitive resilience against Alzheimer's disease. Ann Neurol. 2017:82(4):602-14.

160. Androuin A, Potier B, Nägerl UV, et al. Evidence for altered dendritic spine compartmentalization in Alzheimer's disease and functional effects in a mouse model. Acta Neuropathol. 2018;135(6):839-54.

161. Rodriguez GA, Burns MP, Weeber EJ, Rebeck GW. Young APOE4 targeted replacement mice exhibit poor spatial learning and memory, with reduced dendritic spine density in the medial entorhinal cortex. Learn Mem. 2013; 20(5):256-66.

162. Dumanis SB, Tesoriero JA, Babus LW, et al. ApoE4 decreases spine density and dendritic complexity in cortical neurons in vivo. J Neurosci. 2009;29(48): 15317-22.

163. Wang Y, Manis PB. Synaptic transmission at the cochlear nucleus endbulb synapse during age-related hearing loss in mice. J Neurophysiol. 2005;94(3): 1814-24.

164. Ashford JW. APOE genotype effects on Alzheimer's disease onset and epidemiology. J Mol Neurosci. 2004;23(3):157-66.

165. Shinohara M, Tachibana M, Kanekiyo T, Bu G. Role of LRP1 in the pathogenesis of Alzheimer's disease: evidence from clinical and preclinical studies. J Lipid Res. 2017;58(7):1267-81.

166. Hayashi H, Campenot RB, Vance DE, Vance JE. Apolipoprotein E-containing lipoproteins protect neurons from apoptosis via a signaling pathway involving low-density lipoprotein receptor-related protein-1. J Neurosci. 2007;27(8):1933-41.

167. Sen A, Alkon DL, Nelson TJ. Apolipoprotein E3 (ApoE3) but not ApoE4 protects against synaptic loss through increased expression of protein kinase C epsilon. J Biol Chem. 2012;287(19):15947-58.

168. Ulrich V, Konaniah ES, Herz J, et al. Genetic variants of ApoE and ApoER2 differentially modulate endothelial function. Proc Natl Acad Sci U S A. 2014; 111(37):13493-8.

169. Martinelli N, Olivieri O, Shen G-Q, et al. Additive effect of LRP8/APOER2 R952Q variant to APOE epsilon2/epsilon3/epsilon4 genotype in modulating apolipoprotein E concentration and the risk of myocardial infarction: a casecontrol study. BMC Med Genet. 2009;10(1):41.

170. Nuriel T, Peng KY, Ashok A, et al. The endosomal-lysosomal pathway is dysregulated by APOE4 expression in vivo. Front Neurosci. 2017;11:702.

171. Li J, Kanekiyo T, Shinohara M, et al. Differential regulation of amyloid- $\beta$ endocytic trafficking and lysosomal degradation by apolipoprotein $\mathrm{E}$ isoforms. J Biol Chem. 2012;287(53):44593-601.

172. Belinson H, Lev D, Masliah E, Michaelson DM. Activation of the amyloid cascade in apolipoprotein E4 transgenic mice induces lysosomal activation 
and neurodegeneration resulting in marked cognitive deficits. J Neurosci. 2008;28(18):4690-701.

173. Gilat-Frenkel M, Boehm-Cagan A, Liraz O, et al. Involvement of the Apoer2 and Lrp1 receptors in mediating the pathological effects of ApoE4 in vivo. Curr Alzheimer Res. 2014;11(6):549-57.

174. Maezawa I, Nivison M, Montine KS, Maeda N, Montine TJ. Neurotoxicity from innate immune response is greatest with targeted replacement of E4 allele of apolipoprotein $\mathrm{E}$ gene and is mediated by microglial p38MAPK. FASEB J. 2006;20(6):797-9.

175. Cudaback E, Li X, Montine KS, Montine TJ, Keene CD. Apolipoprotein E isoform-dependent microglia migration. FASEB J. 2011;25(6):2082-91.

176. Bonham LW, Desikan RS, Yokoyama JS, Initiative A's DN. The relationship between complement factor C3, APOE \&4, amyloid and tau in Alzheimer's disease. Acta Neuropathol Commun. 2016;4(1):65.

177. Ungar L, Altmann A, Greicius MD. Apolipoprotein E, gender, and Alzheimer's disease: an overlooked, but potent and promising interaction. Brain Imaging Behav. 2014;8(2):262-73.

178. Kolovou G, Damaskos D, Anagnostopoulou K, Cokkinos DV. Apolipoprotein E gene polymorphism and gender. Ann Clin Lab Sci. 2009;39(2):120-33.

179. Zepa L, Frenkel M, Belinson $H$, et al. ApoE4-driven accumulation of intraneuronal oligomerized A 342 following activation of the amyloid cascade in vivo is mediated by a gain of function. Int J Alzheimers Dis. 2011;2011:792070.

180. Koster KP, Smith C, Valencia-Olvera AC, et al. Rexinoids as therapeutics for Alzheimer's disease: role of APOE. Curr Top Med Chem. 2017:17(6):708-20.

181. Ophir G, Meilin S, Efrati M, et al. Human apoE3 but not apoE4 rescues impaired astrocyte activation in apoE null mice. Neurobiol Dis. 2003;12(1): 56-64.

182. Ulrich JD, Burchett JM, Restivo JL, et al. In vivo measurement of apolipoprotein $\mathrm{E}$ from the brain interstitial fluid using microdialysis. Mol Neurodegener. 2013;8(1):13.

183. Sullivan PM, Han B, Liu F, et al. Reduced levels of human apoE4 protein in an animal model of cognitive impairment. Neurobiol Aging. 2011;32(5):791-801.

184. Zhao N, Liu C-C, Qiao W, Bu G. Apolipoprotein E, receptors, and modulation of Alzheimer's disease. Biol Psychiatry. 2018;83(4):347-57.

185. Doudna JA, Charpentier $E$. The new frontier of genome engineering with CRISPR-Cas9. Science. 2014;346(6213):1258096.

186. Komor AC, Kim YB, Packer MS, Zuris JA, Liu DR. Programmable editing of a target base in genomic DNA without double-stranded DNA cleavage. Nature. 2016;533(7603):420-4.

187. Offen D, Rabinowitz R, Michaelson D, Ben-Zur T. Towards gene-editing treatment for alzheimer's disease: ApoE4 allele-specific knockout using CRISPR cas9 variant. Sci Direct. 2018;20(5):S18.

188. Tachibana M, Shinohara M, Yamazaki Y, et al. Rescuing effects of RXR agonist bexarotene on aging-related synapse loss depend on neuronal LRP1. Exp Neurol. 2016;277:1-9.

189. Talwar P, Silla Y, Grover $S$, et al. Genomic convergence and network analysis approach to identify candidate genes in Alzheimer's disease. BMC Genomics. 2014;15(1):199.

190. Chen Q, Liang B, Wang Z, et al. Influence of four polymorphisms in ABCA1 and PTGS2 genes on risk of Alzheimer's disease: a meta-analysis. Neurol Sci. 2016;37(8):1209-20.

191. Van den Bossche T, Sleegers K, Cuyvers E, et al. Phenotypic characteristics of Alzheimer patients carrying an ABCA7 mutation. Neurol. 2016;86(23):2126-33.

192. Kim J, Eltorai AEM, Jiang $H$, et al. Anti-apoE immunotherapy inhibits amyloid accumulation in a transgenic mouse model of $A \beta$ amyloidosis. J Exp Med. 2012;209(12):2149-56.

193. Liao F, Hori Y, Hudry E, et al. Anti-ApoE antibody given after plaque onset decreases $A \beta$ accumulation and improves brain function in a mouse model of $A \beta$ amyloidosis. J Neurosci. 2014;34(21):7281-92.

194. Luz I, Liraz O, Michaelson DM. An anti-apoE4 specific monoclonal antibody counteracts the pathological effects of apoE4 in vivo. Curr Alzheimer Res. 2016;13(8):918-29.

195. Chen H-K, Liu Z, Meyer-Franke A, et al. Small molecule structure correctors abolish detrimental effects of apolipoprotein E4 in cultured neurons. J Biol Chem. 2012;287(8):5253-66.

196. Huang Y, Liu XQ, Wyss-Coray T, et al. Apolipoprotein E fragments present in Alzheimer's disease brains induce neurofibrillary tangle-like intracellular inclusions in neurons. Proc Natl Acad Sci U S A. 2001;98(15):8838-43.

197. Harris FM, Brecht WJ, Xu Q, et al. Carboxyl-terminal-truncated apolipoprotein E4 causes Alzheimer's disease-like neurodegeneration and behavioral deficits in transgenic mice. Proc Natl Acad Sci U S A. 2003; 100(19):10966-71.

198. Gonneaud J, Arenaza-Urquijo EM, Fouquet M, et al. Relative effect of APOE $\varepsilon 4$ on neuroimaging biomarker changes across the lifespan. Neurol. 2016; 87(16):1696-703.

199. Kantarci K, Lowe V, Przybelski SA, et al. APOE modifies the association between $A \beta$ load and cognition in cognitively normal older adults. Neurol. 2012;78(4):232-40.

200. Murphy KR, Landau SM, Choudhury KR, et al. Mapping the effects of ApoE4, age and cognitive status on 18F-florbetapir PET measured regional cortical patterns of beta-amyloid density and growth. Neuroimage. 2013;78:474-80.

201. Serrano-Pozo A, Qian J, Monsell SE, Betensky RA, Hyman BT. APOEE2 is associated with milder clinical and pathological Alzheimer disease. Ann Neurol. 2015;77(6):917-29.

202. Kim J, Basak JM, Holtzman DM. The role of apolipoprotein E in Alzheimer's disease. Neuron. 2009;63(3):287-303.

203. Fleisher AS, Chen K, Liu X, et al. Apolipoprotein E $\varepsilon 4$ and age effects on florbetapir positron emission tomography in healthy aging and Alzheimer disease. Neurobiol Aging. 2013;34(1):1-12.

204. Huang Y, Mahley RW. Apolipoprotein E: structure and function in lipid metabolism, neurobiology, and Alzheimer's diseases. Neurobiol Dis. 2014;72:3-12.

205. Sadowski M, Pankiewicz J, Scholtzova H, et al. Links between the pathology of Alzheimer's disease and vascular dementia. Neurochem Res. 2004;29(6): 1257-66.

206. Liao F, Li A, Xiong M, et al. Targeting of nonlipidated, aggregated apoE with antibodies inhibits amyloid accumulation. J Clin Invest. 2018;128(5):2144-55.

207. Verghese PB, Castellano JM, Garai K, et al. ApoE influences amyloid- $\beta$ (A $\beta$ ) clearance despite minimal apoE/A $\beta$ association in physiological conditions. Proc Natl Acad Sci U S A. 2013;110(19):E1807-16.

208. Ruiz J, Kouiavskaia D, Migliorini M, et al. The apoE isoform binding properties of the VLDL receptor reveal marked differences from LRP and the LDL receptor. J Lipid Res. 2005;46(8):1721-31.

209. Bachmeier C, Shackleton B, Ojo J, et al. Apolipoprotein E isoform-specific effects on lipoprotein receptor processing. NeuroMolecular Med. 2014;16(4): 686-96.

210. He X, Cooley K, Chung CHY, Dashti N, Tang J. Apolipoprotein receptor 2 and $\mathrm{X} 11$ alpha/beta mediate apolipoprotein E-induced endocytosis of amyloid-beta precursor protein and beta-secretase, leading to amyloid-beta production. J Neurosci. 2007;27(15):4052-60.

211. Ghosal K, Stathopoulos A, Thomas D, et al. The apolipoprotein-E-mimetic COG112 protects amyloid precursor protein intracellular domainoverexpressing animals from Alzheimer's disease-like pathological features. Neurodegener Dis. 2013;12(1):51-8.

212. Vitek MP, Christensen DJ, Wilcock D, et al. APOE-mimetic peptides reduce behavioral deficits, plaques and tangles in Alzheimer's disease transgenics. Neurodegener Dis. 2012;10(1-4):122-6.

213. Wang W, Zhu X. HDL mimetic peptides affect apolipoprotein E metabolism: equal supplement or functional enhancer?: an editorial for 'High-density lipoprotein mimetic peptide $4 \mathrm{~F}$ mitigates amyloid- $\beta$-induced inhibition of apolipoprotein $\mathrm{E}$ secretion and lipidation in primary astrocytes and microglia' on page 647. J Neurochem. 2018;147(5):580-3.

214. Laskowitz DT, Song P, Wang H, et al. Traumatic brain injury exacerbates neurodegenerative pathology: improvement with an apolipoprotein $\mathrm{E}$ based therapeutic. J Neurotrauma. 2010;27(11):1983-95.

215. Yao X, Vitek MP, Remaley AT, Levine SJ. Apolipoprotein mimetic peptides: a new approach for the treatment of asthma. Front Pharmacol. 2012;3:37.

216. Wang $H$, Anderson LG, Lascola CD, et al. Apolipoprotein E mimetic peptides improve outcome after focal ischemia. Exp Neurol. 2013;241:67-74.

217. White CR, Garber DW, Anantharamaiah GM. Anti-inflammatory and cholesterol-reducing properties of apolipoprotein mimetics: a review. J Lipid Res. 2014;55(10):2007-21.

218. Rebeck GW, Kindy M, LaDu MJ. Apolipoprotein E and Alzheimer's disease: the protective effects of ApoE2 and E3. J Alzheimers Dis. 2002;4(3):145-54.

219. Drenos F, Kirkwood TBL. Selection on alleles affecting human longevity and late-life disease: the example of apolipoprotein E. PLoS One. 2010;5(4):e10022.

220. Suri S, Heise V, Trachtenberg AJ, Mackay CE. The forgotten APOE allele: a review of the evidence and suggested mechanisms for the protective effect of APOE ع2. Neurosci Biobehav Rev. 2013:37(10 Pt 2):2878-86.

221. Dodart J-C, Marr RA, Koistinaho M, et al. Gene delivery of human apolipoprotein E alters brain Abeta burden in a mouse model of Alzheimer's disease. Proc Natl Acad Sci U S A. 2005;102(4):1211-6. 
222. Rosenberg JB, Kaplitt MG, De BP, et al. AAVrh.10-mediated APOE2 central nervous system gene therapy for APOE4-associated Alzheimer's disease. Hum Gene Ther Clin Dev. 2018;29(1):24-47.

223. Keren-Shaul H, Spinrad A, Weiner A, et al. A unique microglia type associated with restricting development of Alzheimer's disease. Cell. 2017; 169(7):1276-90.e17.

224. Brown GC, St George-Hyslop PH. Deciphering microglial diversity in Alzheimer's disease. Science. 2017;356(6343):1123-4.

225. Wattananit S, Tornero D, Graubardt N, et al. Monocyte-derived macrophages contribute to spontaneous long-term functional recovery after stroke in mice. J Neurosci. 2016;36(15):4182-95.

226. Altman R, Rutledge JC. The vascular contribution to Alzheimer's disease. Clin Sci. 2010;119(10):407-21

227. Rohn TT. Is apolipoprotein E4 an important risk factor for vascular dementia? Int J Clin Exp Pathol. 2014;7(7):3504-11.

228. Mahley RW, Weisgraber KH, Huang Y. Apolipoprotein E: structure determines function, from atherosclerosis to Alzheimer's disease to AIDS. J Lipid Res. 2009;50(Supplement):S183-8.

229. Sengillo JD, Winkler EA, Walker $C T$, et al. Deficiency in mural vascular cells coincides with blood-brain barrier disruption in Alzheimer's disease. Brain Pathol. 2013;23(3):303-10.

230. Davey DA. Alzheimer's disease and vascular dementia: one potentially preventable and modifiable disease? Part II: management, prevention and future perspective. Neurodegener Dis Manag. 2014;4(3):261-70.

231. Theendakara V, Peters-Libeu CA, Spilman P, et al. Direct transcriptional effects of apolipoprotein E. J Neurosci. 2016;36(3):685-700.

232. Parcon PA, Balasubramaniam M, Ayyadevara S, et al. Apolipoprotein E4 inhibits autophagy gene products through direct, specific binding to CLEAR motifs. Alzheimers Dement. 2018;14(2):230-42.

233. Urfer-Buchwalder A, Urfer R. Identification of a nuclear respiratory factor 1 recognition motif in the apolipoprotein E variant APOE4 linked to Alzheimer's disease. Sci Rep. 2017;7(1):40668.

234. Rohn TT, Moore ZD. Nuclear localization of apolipoprotein E4: a new trick for an old protein. Int J Neurol Neurother. 2017;4(2). https://doi.org/10. 23937/2378-3001/1410067.

235. Theendakara V, Peters-Libeu CA, Bredesen DE, Rao RV. Transcriptional effects of ApoE4: relevance to Alzheimer's disease. Mol Neurobiol. 2018;55(6):5243-54.

236. Singhrao SK, Harding A, Chukkapalli S, et al. Apolipoprotein E related comorbidities and Alzheimer's disease. J Alzheimers Dis. 2016;51(4):935-48.

Ready to submit your research? Choose BMC and benefit from:

- fast, convenient online submission

- thorough peer review by experienced researchers in your field

- rapid publication on acceptance

- support for research data, including large and complex data types

- gold Open Access which fosters wider collaboration and increased citations

- maximum visibility for your research: over $100 \mathrm{M}$ website views per year

At $\mathrm{BMC}$, research is always in progress.

Learn more biomedcentral.com/submissions 